\title{
Entre el autogobierno y el Estado. Las instituciones y el desarrollo económico ${ }^{1}$
}

\author{
Domingo GALLEGO \\ Universidad de Zaragoza \\ dgallego@unizar.es
}

Received: 05/08/2016

Accepted: 02/11/2016

\begin{abstract}
Resumen
En este trabajo se pretende ofrecer una imagen general de las distintas tendencias de la economía institucional. El objetivo es mostrar sus complementariedades, es decir, en qué medida ha ido surgiendo un cuerpo general coherente y relevante para el análisis histórico. Se han seleccionado las propuestas de un amplio grupo de autores y se han intentado engarzar argumentalmente. Se trata sucesivamente de la capacidad de autogobierno de las sociedades, es decir de la acción individual y de la colectiva, y también de la acción pública. Se muestran las interacciones entre ellas y sus respectivos problemas y potencialidades. El hilo argumental del trabajo vincula las instituciones con la selección, producción y mantenimiento de bienes públicos y colectivos y a través de ellos con los modos de cooperar y el desarrollo económico.
\end{abstract}

Palabras clave: normas, orden espontáneo, acción colectiva, Estado, sistema político, bienes públicos, comunes

Clasificación JEL: B52, B53, H41, P32

\section{Between self-government and the State. Institutions and economic development}

\begin{abstract}
This essay is intended to offer a general view of the different tendencies of the institutional economy. The aim is to show its complementarities, that is, to determine to what extent a relevant and coherent general body of work for the historical analysis has arisen. The proposals of a wide group of authors have been selected and efforts have been made to tie them in arguably. It deals first with the capacity of self-government of the societies, that is, the individual and collective action, and then, with the public action. The interaction between them and their respective problems and potentials are shown. The thematic thread of the essay links the institutions with the selection, production and the maintenance of the public and collective goods, and through them, the way of cooperation and the economic development.
\end{abstract}

Keywords: rules, spontaneous order, collective action, State, political system, public good, commons

JEL Classification: B52, B53, H41, P32

\section{Introducción}

El desarrollo económico nos remite a la complejidad de las sociedades. Muchas cosas deben ir bien o muy bien en una sociedad para lograr combinar una mejora sostenida en las condiciones de vida del conjunto de su población con una relación con la naturaleza y con otros pueblos enriquecedora para todos.

\footnotetext{
${ }^{1}$ Una versión anterior de este artículo se publicó en 2014 con el título "Las distintas caras de la economía institucional" en la colección de documentos de trabajo de la Asociación Española de Historia Económica (DT-AEHE, $\mathrm{n}^{\circ}$ 1412): http://www.aehe.es/wp-content/uploads/2015/04/dt-aehe-1412.pdf

Este trabajo es deudor de los comentarios de los evaluadores anónimos de Iberian Journal of the History of Economic Thought y de los Documentos de trabajo de la AEHE. En 2013 la versión inicial del trabajo se presentó a la sesión sobre "Instituciones y desarrollo económico" celebrada en el contexto del XV Congreso de Historia Agraria. Agradezco a Francisco Beltrán, Salvador Calatayud y Samuel Garrido, relatores de aquella sesión, sus comentarios. Las sugerencias de José Ignacio Jiménez Blanco, Eduardo Sanz Arcega, María Pilar Marcos y Ángel Gallego Marcos también me fueron de mucha utilidad. A todos ellos les agradezco sinceramente su desinteresada ayuda.
} 
El objetivo de este trabajo se centrará en entrelazar las aportaciones de la economía institucional respecto a la acción individual, la acción colectiva y la pública. Es decir, se pretende mostrar que el contexto que regula el funcionamiento de la economía de mercado y le nutre de bienes públicos e induce a la preservación de los comunes no es meramente la acción pública. Potencialmente al menos, tan importante como ella es la transmisión y paulatina modificación cotidiana de norma que tiene lugar al compás de las relaciones entre particulares y organizaciones; o mediante las acciones colectivas que desarrollan gran diversidad de agentes y organizaciones. Además, los agentes, tanto a través de su comportamiento individual como de las acciones colectivas que organizan, proveen a la sociedad de una amplia diversidad de bienes públicos pues al cuidar de su salud o su educación, o al inducir a otros a hacerlo, como al cumplir las normas o al ser considerados con la naturaleza están de hecho preservando y potenciando una gran diversidad de bienes públicos y comunes. La acción pública se entretejerá por lo tanto con las acciones individuales y colectivas condicionándose mutuamente.

Quizá los autores que más han aportado para favorecer esta visión compleja de la sociedad sean North (1990 y 2005) con el carácter central que otorga a las normas informales y a los instrumentos de pensamiento en el funcionamiento de las sociedades; Hayek (1973) con su noción de orden espontáneo; y Ostrom (1990) con su recuperación de la acción colectiva a través del análisis de la gestión de los bienes comunes. Los tres, junto a otros autores a los que iremos recurriendo para completar y matizar estas propuestas, nos muestran una capacidad de autogobierno de las sociedades que habían pasado por alto por muchos economistas cuando proponían al Estado y al mercado como únicas alternativas para la gestión de los recursos o para reglamentar el comportamiento de los agentes económicos.

El estado actual de la economía institucional nos brinda así instrumentos conceptuales para percibir y poder analizar aspectos del funcionamiento de las sociedades vitales para entender sus pautas de desenvolvimiento y que habían sido dejados de lado tanto en la discusión académica como en el diseño de las políticas públicas (Ostrom 2010). En este contexto, para sistematizar las fuerzas que actúan sobre la acción pública, no habrá que situarla tan solo en el contexto de las características organizativas del Estado y del sistema político; también habrán de considerarse los procesos descentralizados y persistentes que van de abajo a arriba y que condicionan tanto los criterios por los que se rigen los políticos y funcionarios públicos como los instrumentos de pensamiento que utilizan para sus procesos de toma de decisiones. También la acción colectiva incidirá en la pública vía su capacidad de información y control de las administraciones públicas y a través de la capacidad de la acción colectiva de transformar los valores sociales. En el análisis de la acción colectiva la posición de autores como Olson (1971) y Ostrom (1990) resultan dispares, pero como veremos, conciliables.

Siguiendo a North (1990), suponemos que el núcleo de cualquier sistema institucional -y el bien público y común básico- serán los criterios que orientan el comportamiento de las personas, es decir, tanto las normas -las informales y las formales-como los instrumentos de pensamiento que las sociedades ofrecen a sus miembros (North, 2005). También irán incluidos en el concepto de instituciones los muy diversos sistemas que inducen a que los comportamientos sean coherentes con las normas y criterios establecidos (Ostrom, 2005, pp. 343-406). ${ }^{2}$ Todas estas normas, modos de pensar y sistemas de control del comportamiento se originarán, consciente o inconscientemente, en una gran diversidad de experiencias y de acciones individuales, colectivas y públicas. ${ }^{3}$

El hilo conductor del trabajo, muy influido por las propuestas de Olson (2000) y Ostrom (2005), será la vinculación de las instituciones con la selección y producción de bienes públicos

\footnotetext{
${ }^{2}$ Se incluirían así también en el concepto de instituciones las redes sociales pues, aunque son caminos para la circulación de información, lo son también para mejorar el nivel de conocimiento y control de unos sobre otros (Granovette, 1973; Putman, 2002, 544-561 y Ostrom y Ahn, 2003).

${ }^{3}$ Para un análisis abierto del concepto de instituciones véase Alonso y Garcimartín (2008, pp. 59-72).
} 
y con la gestión de los comunes. ${ }^{4}$ Es decir, las prioridades sobre qué bienes públicos producir y que bienes comunes preservar, así como la inducción de los comportamientos que conduzcan a esos objetivos, estarán contenidos en los criterios, normas e instrumentos de pensamiento que orientan a los miembros de cualquier sociedad. Implícitamente este razonamiento implica que la relación entre instituciones y desarrollo económico estará mediada por la dotación de bienes públicos y comunes, pues dicha dotación influirá tanto en los modos de cooperación -tanto para la producción de bienes públicos como privados- como en sus consecuencias sociales y ambientales. ${ }^{5}$

En la primera parte del texto (epígrafe 2) se tratará de la capacidad de autogobierno de las sociedades, es decir de la acción individual y de la colectiva, y en la segunda (epígrafe 3) de la acción pública. En ambos casos se dará especial importancia a las circunstancias que inducen o impiden un funcionamiento social y ambientalmente equilibrado de cada uno de esos ámbitos de construcción del entramado institucional de una sociedad. ${ }^{6}$

\section{El autogobierno de las sociedades o la dinámica institucional descentralizada}

En este epígrafe se tratará sucesivamente de la acción individual y de la colectiva. El hilo argumental comienza presentando los procesos de formación de las normas informales, posteriormente se analizarán los modos de autocontrol y de control social descentralizado inductores de su cumplimiento (sub-epígrafe 2.1). En el sub-epígrafe 2.2 se trata de la acción colectiva tanto desde la perspectiva crítica de Olson y Hardin, como desde la más optimista inducida por los trabajos de Ostrom.

\subsection{La acción individual y el orden espontáneo}

\section{La formación y transmisión de las normas}

Hace ya tiempo Hayek (1973, vol. I, pp. 141-157) señalaba cómo las normas informales que condicionan el comportamiento y hacen viable la sociedad debieron de ser anteriores al lenguaje. Los nuevos miembros de un grupo humano, incluso con la ausencia de lenguaje, tenderían a sistematizar en normas los comportamientos observados en los mayores. Unos y otros a su vez desarrollarían comportamientos específicos en respuesta a las actuaciones de los otros. Así todos podrían ir percibiendo cómo eran valoradas sus conductas por los demás.

Un estudio más reciente basado en el comportamiento de niños muy pequeños y primates (Tomasello, 2010) confirma esta tendencia a convertir en normas los comportamientos observados y, complementariamente, una tendencia innata a la cooperación entre los más pequeños y de estos con los mayores, favorecedora en ambos casos de su integración en el grupo. Pese a ello, en fases posteriores de su socialización, esta tendencia general a la cooperación se puede matizar y hacerse más selectiva dependiendo de las características del grupo.

Desde la perspectiva de la teoría de los juegos, Binmore (2009, pp. 93-139) indica cómo los sistemas de normas de los que se va dotando de modo espontáneo una sociedad pueden interpretarse como convenciones resultantes de las soluciones encontradas a los juegos no cooperativos implícitos en las relaciones sociales. Mediante largos procesos de interacción y de prueba y error los miembros de una sociedad van encontrando problemas interpersonales al organizar la

\footnotetext{
4 Esta línea argumental es deudora también de la lectura del capítulo 3 "Lo común en el centro del análisis frente a la dicotomía Estado-mercado" de la tesis doctoral de Alba Delgado Riaño (Delgado, 2015, pp. 75-120)

${ }^{5}$ En el análisis de la relación entre las instituciones y el desarrollo económico puede ser útil acudir a las propuestas de la economía evolutiva. Remito al análisis de la coevolución entre instituciones y economía que propone Nelson (2008).

${ }^{6}$ El destacar en el texto el papel de las acciones individuales y colectivas, junto a las públicas, en el proceso de construcción del entramado institucional de las sociedades y en la provisión de los demás bienes públicos y colectivos, no implica propuesta política alguna; solo se pretende mostrar que si queremos entender qué pasa y dar pasos para mejorar hay que considerar ámbitos que no han sido frecuentemente tenidos en cuenta. Desde mi experiencia como agrarista mi impresión es que las sociedades más diversas, es decir, que utilizan y potencian cooperativamente los distintos modos de organizarse, tienden a ser más capaces de reaccionar ante las dificultades y de prosperar (Gallego, 2007, 201-206).
} 
cooperación entre ellos, y paulatinamente van seleccionando modos de darles soluciones. Al igual que se sistematizan y transmiten experiencias tecnológicas o conocimientos útiles sobre el medio natural, ocurre otro tanto con aquellas pautas de comportamiento que, siendo solución para los problemas de un momento concreto, lo puedan ser también para situaciones similares futuras. Las sociedades y sus individuos van así acumulando y transmitiendo experiencias que permiten ir dando soluciones concretas a multitud de problemas presentes y futuros (Auman 2012, pp. 25-41). En este proceso cada grupo irá configurando sus peculiares rasgos que a su vez condicionarán su evolución.

Desde una perspectiva filosófica Gauthier (1997) intenta demostrar cómo los intereses personales de un conjunto de individuos egoístas y racionales les inducirían a establecer un conjunto de normas que hagan viable la cooperación entre ellos. Estas normas, aunque restringirían la libertad individual, podrían ser aceptadas por todos ya que, gracias a ellas, se podrían desarrollar proyectos más atractivos que resultarían inviables sin una vida social dotada de cierto orden y estabilidad. Gauthier no entra en analizar el proceso histórico que conduciría a este resultado, se mantiene en un plano exclusivamente lógico, pero nos ofrece una perspectiva adicional para entender por qué los individuos, incluso los egoístas racionales, tienen incentivos para aceptar normas que condicionan su comportamiento. Esta línea argumental es indudablemente heredera de la planteada por Hume (1739-1740, pp. 652-673).

Estos incentivos para aceptar o acordar normas se combinan con la inmersión en las normas y criterios morales de una sociedad desde el momento que al nacer nos incorporamos a ella. En este caso no hay elección, sino que nuestro propio ser, e incluso como veremos nuestra capacidad de analizar, se constituye en esta interacción con los otros (Douglas, 1986). Es evidente pues que las normas sociales heredadas condicionan el futuro de la sociedad con sus potentes inercias, pues incluso la selección de nuevas normas se realizará desde los criterios de las anteriores. Esta relación entre la elección de normas y las restricciones culturales que la condicionan permite combinar las propuestas de Gauthier y Douglas. La elección desde un individuo limpio de influencias externas que nos plantea Gauthier no sería muy razonable desde una perspectiva histórica; el considerar a los individuos como meros receptores de normas heredadas tampoco.

En definitiva, tanto las normas que surgen espontáneamente de la interacción social como las elegidas se van formando condicionadas por las normas anteriores, es decir, por las características culturales del entorno en el que se forman. Cada grupo irá así configurando sus peculiares rasgos y sendas de evolución condicionado de distinto modo el comportamiento de sus miembros. Los resultados de estas distintas evoluciones se perciben con especial claridad en los juegos diseñados con criterios conductistas (Henrich et al., 2001): al diseñar varios juegos, seleccionando sucesivamente jugadores procedentes de distintas culturas y entornos económicos, se aprecia como los resultados difieren, tras estas diferencias estarían los dispares criterios y normas manejados por las personas en sus procesos de toma de decisiones.

North (1990) sitúa a su vez a las normas informales como pieza central de una sociedad, ${ }^{7}$ y en concreto insiste en su capacidad explicativa de las distintas sendas de desarrollo económico seguidas por las sociedades en el largo plazo. Las normas son leídas por North como sistemas de incentivos que incidirán considerablemente en las decisiones de las personas y de las organizaciones. Es decir, influirán en que en las relaciones entre los agentes económicos sean de tipo inclusivo o extractivo (Acemoglu y Robinson, 2012, pp. 91-120), y en la magnitud de los costes de transacción y agencia derivados de establecerlas y sostenerlas (Coase, 1937 y 1960 y Williamson, 1985). Por lo tanto, tras las características de las normas se encontrarían las capacidades de algunas sociedades de crecer en renta y bienestar en favor de la inmensa mayoría de la población, y los problemas de otras en las que persistirían el atraso y los graves desequilibrios sociales.

Pero las normas informales, al ser consecuencia de la experiencia, es decir, de las relaciones sociales concretas en las que se han ido conformando, no son ajenas a los posibles desequili-

\footnotetext{
${ }^{7}$ La influencia de las normas informales sobre el comportamiento es por un lado directa y, por otro, indirecta al influir sobre los modos de cumplimiento efectivo de las normas formales (North, 1990, 17).
} 
brios interpersonales que puedan existir. Bhaduri (1998) señala que, para que los resultados de las negociaciones no resulten demasiado desequilibrados, es clave que las partes dispongan de oportunidades alternativas a la relación que haya provocado el conflicto. Disponer de otras oportunidades permite no tener que conformarse con las propuestas de los más poderosos. Estos a su vez, conocedores de las alternativas de las que los otros disponen, tenderán a ser más considerados en sus propuestas. El razonamiento de Bhaduri nos permite percibir la interacción entre las normas y las relaciones sociales. Las normas respetuosas con los derechos de los demás tenderían a diluirse en sociedades muy desequilibradas socialmente; las normas muy desequilibradas tenderían a matizarse si las circunstancian o sus iniciativas abriesen nuevos abanicos de oportunidades a los menos favorecidos.

En cualquier caso, la resultante de la interacción entre normas y desigualdad no es algo que pueda preverse mecánicamente al ser una relación mediada por las acciones individuales y colectivas de los distintos agentes y por las oportunidades que puedan ir apareciendo para unos y otros (Bhaduri, 1998 y Sen, 1995 y 1999). El cambio tecnológico, por ejemplo, al ser un potente factor de modificación de la funcionalidad productiva de las relaciones sociales, de las habilidades humanas y de los recursos naturales podrá abrir o cerrar oportunidades a las distintas personas, favoreciendo con ello el cambio de las normas y valores que ordenan y orientan la cooperación entre ellos (Morris, 2016). Pero también, como señalaría North, las características de las normas y de los valores sociales pueden frenar o potenciar el desenvolvimiento tecnológico de una sociedad. ${ }^{8}$ Esto último se aprecia particularmente al analizar la distinta cronología espacial del desarrollo económico, y no tanto al observar las características generales de los valores de las sociedades industrializadas -o de las anteriores- que es el objeto de estudio de Morris. ${ }^{9}$

Hayek (1973, vol. I, pp. 75-108), con su concepto de orden espontáneo nos da claves útiles para analizar el proceso de formación de las normas sociales como resultado del entrelazamiento de comportamientos y relaciones entre todos los agentes sociales. Además, nos ofrece elementos para valorar la relevancia económica de estas cuestiones.

Nos muestra a cualquier sociedad como un conjunto muy complejo. Hay gran cantidad de individuos con sus peculiares caracteres, experiencias y capacidades; contextos naturales muy variados con sus peculiares características; gran variedad de tipos y orientaciones productivas de empresas. Incluso dentro de una sociedad hay muy diversos tipos de ambientes con sus correspondientes peculiaridades normativas; las mismas tecnologías son a su vez usadas de modos muy variados.

En cualquier sociedad, señala Hayek, hay pues una gran cantidad de información dispersa que ningún agente u organización puede llegar a conocer y a aprovechar globalmente. En este contexto la planificación central quizá sea posible, pero será seguro enormemente ineficiente, pues se tomarán decisiones desconociendo buena parte de la información relevante para actuar de modo eficaz. Tampoco sería eficiente la legislación muy ordenancista que intentase regular múltiples pequeños aspectos de modo general para el conjunto de la sociedad.

En los anteriores argumentos aflora el miedo al Estado de Hayek, pero además de eso nos presenta un brillante análisis de cómo la acción individual descentralizada puede desenvolverse eficazmente en este contexto de información tan dispersa. Cada individuo se conoce a sí mismo y a las personas con las que se relaciona, conoce los problemas concretos del área profesional, territorial y social en la que actúa. Lo mismo cabe decir para las organizaciones y empresas.

El orden espontáneo sería así una consecuencia de la combinación entre dispersión de la información y la descentralización de las decisiones. Cada cual, individuo o empresa, toma decisiones desde el conocimiento del entorno en el que se desenvuelve. Tenderá así a aprovechar adecuadamente las capacidades propias y las de los agentes con los que se relaciona.

\footnotetext{
${ }^{8} \mathrm{El}$ análisis del contexto en el que se fue formando la "Ilustración Industrial" durante la segunda mitad del siglo XVIII en es un buen ejemplo de las condiciones favorecedoras del cambio tecnológico que, desde luego, no eran solo institucionales (Mokyr, 2002, pp. 45-70).

${ }^{9}$ Morris (2016) realiza un análisis de la historia de la humanidad a vuelo de pájaro con el objetivo de mostrarnos como los modos de proveerse de energía condiciona profundamente los valores que han ido rigiendo en las sociedades de cazadores recolectores, campesinas e industriales.
} 
Estas relaciones se adaptarán a las normas preexistentes en cada ámbito de la sociedad, pero la propia experiencia de nuevos problemas o nuevas necesidades, las irá modificando en paralelo al desarrollo de nuevas capacidades propias o ajenas que irán surgiendo también como consecuencia de la mutua cooperación.

En este sentido el orden espontáneo es para Hayek un modo eficaz y dinámico de aprovechar las capacidades de una sociedad. Nadie podrá conocer el conjunto del sistema, pero cada uno, lejos de conformarse con su entorno cotidiano, oteará las oportunidades de cooperar con otros agentes, o de actuar en otros ámbitos, o intentará matizar las normas que cree que no le resultan adecuadas. La corriente austriaca percibe el orden espontáneo desarrollado en una sociedad de libre mercado como algo especialmente eficaz, y la intervención pública excesiva como algo extremadamente peligroso para el correcto aprovechamiento de las capacidades de una sociedad.

Pero si dejamos de lado por el momento las implicaciones políticas que Hayek y también Mises (1947) sacan de este análisis del orden espontáneo, y nos quedamos con la rica imagen que nos transmite del funcionamiento de las sociedades, tendremos un instrumento muy adecuado para analizar cómo en esas relaciones y decisiones descentralizadas se van formando y corrigiendo las normas informales, se va generando rutinas técnicas y sociales, se van produciendo y transmitiendo ideas y experiencias que permiten observar desde nuevas perspectivas el entorno. Pero esto a su vez no tiene lugar tan solo en ámbitos mercantiles y productivos. La lógica de estas relaciones descentralizadas actúa en la vida familiar, cultural, científica o religiosa y en estos aspectos las normas y las ideas también irán siendo revisadas.

Es decir, el concepto de orden espontáneo nos permite interesarnos por esos aspectos cotidianos y privados que se desarrollan en todos los ámbitos de la vida social y que, a su vez, tienen una enorme capacidad explicativa, pues son fuerzas persistentes, que actúan día tras día -como la persistente fuerza erosiva del viento o el mar- y cuyas consecuencias, al no ser percibidas mucho más allá de los ámbitos en los que se generan, son difícilmente removibles por agentes externos públicos o privados que actúen desde otros ámbitos. La hipótesis implícita en el concepto de orden espontáneo es que buena parte de las características de las sociedades son consecuencia del trato cotidiano entre los agentes en esos múltiples mundos pequeños.

Pero puede ser peligroso idealizar estos comportamientos descentralizados, pues sus características y resultados están marcados por los desequilibrios en el acceso a los recursos, a la formación, a la información o por desequilibrios de poder entre las personas y las organizaciones, pudiendo concretarse también esos desequilibrios en la generación de normas informales discriminatorias. Es conveniente pues retirar del concepto de orden espontáneo su percepción, tan característica de los economistas austriacos, como un orden no inmejorable pero sí que resulta inadecuado modificar mediante la acción pública, pues implicaría sustituir los resultados de la interacción libre de todos por los criterios de unos pocos que se imponen a la colectividad. Para estos autores solo cabría la intervención pública para defender la libertad individual, evitando la coacción y la violencia en las relaciones entre los agentes. Es decir, Hayek (1976 vol. II, pp. 119-123) es consciente de los desequilibrios sociales pero no piensan que se deban corregir desde el Estado. Así señala que la noción de justicia puede aplicarse al comportamiento individual pero no a los resultados del orden espontáneo, siempre que este se desenvuelva en un ámbito de libertades individuales.

\section{Sobre las circunstancias que inducen al cumplimiento de las normas}

Hasta ahora solo hemos analizado la capacidad normativa descentralizada de los agentes sociales; ahora debemos completar esta perspectiva con el análisis de los modos de inducir al cumplimiento de las normas. Para ello recurriremos al concepto de cooperadores condicionales (Ostrom, 2005, pp. 343-406), es decir a una visión compleja de las fuerzas que guían los comportamientos de los agentes que nos los muestra como personas al mismo tiempo morales, sociales y egoístas, y también, como se verá al final de este sub-epígrafe, como personas con su peculiar bagaje de conocimientos, rutinas, experiencias e información.

Como personas morales tienen códigos de conducta asumidos, visiones de lo que resulta correcto o incorrecto hacer o no hacer, decir o no decir. Todo esto no solo para asuntos cotidianos 
que le vayan surgiendo, también para elegir y diseñar proyectos a largo plazo. Dependiendo del carácter de cada cual y del entorno en el que se haya formado, estos criterios morales serán de un tipo u otro, y tendrán mayor o menor fuerza como condicionantes de los procesos de toma de decisiones individuales. Explícitamente esta línea argumental implica que ser coherente con los propios criterios morales transmite satisfacción y no serlo autocensura, cargo de conciencia, insatisfacción en definitiva.

Además, como personas sociales, todos estaríamos preocupados por nuestra reputación, es decir, por la imagen que los demás tengan de uno mismo o de su empresa. Esta preocupación estaría motivada por causas principalmente egoístas, pues la buena reputación es fuente no solo de prestigio, sino también de oportunidades profesionales o empresariales. Es decir, la buena reputación puede ser una fuente de ingresos, mientras que la mala puede generar paro, empleos poco atractivos y mal pagados y para las empresas huida de inversores y pérdidas de clientes y de buenos proveedores. ${ }^{10} \mathrm{La}$ reputación es pues un patrimonio inmaterial que conviene cuidar si se quiere prosperar no solo en el ámbito mercantil sino también en el político, científico, religioso o familiar. ${ }^{11}$

La reputación de las personas o empresas las conocen quienes tienen trato cotidiano con ellas - es decir, cada cual tiene una imagen de qué se puede esperar de las personas u organizaciones con las que se relaciona con frecuencia-. Pero también la pueden conocer agentes ajenos, incluso muy distantes de los círculos cotidianos, pues puede haber canales, más o menos abundantes, dependiendo del tipo de sociedad, a través de los cuales personas lejanas pueden llegar a estar al corriente del estado de opinión sobre las capacidades y fiabilidad de las personas u organizaciones con las que estén pensando cooperar.

En definitiva, la reputación no solo actúa como condicionante de los comportamientos en el ámbito de las relaciones cotidianas con las personas o con las empresas con las que se está más implicado. La reputación puede actuar también como inductora al cumplimiento de las normas en las relaciones con agentes lejanos o de trato poco cotidiano, es decir, la reputación puede inducir a comportamientos fiables incluso en ámbitos sociales extensos, sobre todo en contextos ricos en vínculos débiles entre agentes (Granovette, 1973). ${ }^{12}$ La amplia información disponible a través de internet sobre personas y organizaciones refuerza la preocupación por los efectos en reputación de los comportamientos, independientemente del ámbito próximo o lejano en el que las personas o empresas se desenvuelvan.

Además, puede darse una interacción, potencialmente positiva, entre reputación y valores morales, ya que el actuar reiteradamente de modo coherente con las normas para mantener y mejorar la reputación, y el ver hacer lo mismo a los demás, irá provocando la internalización de las normas como códigos morales, por lo que se tenderán a cumplir sin necesidad de cálculos egoístas. En algunos casos, dependiendo de las características de la norma afectada, también podrán convertirse en rutinas cuyo cumplimiento casi pasará desapercibido a las personas que se comportan de acuerdo con ellas.

Ostrom (2005, pp. 343-406) integra el conjunto de factores inductores del cumplimiento o incumplimiento de las normas en un cálculo global orientado por los móviles egoístas de los cooperadores condicionales. Así establece un parámetro delta que representa para cada indivi-

\footnotetext{
${ }^{10} \mathrm{El}$ concepto de responsabilidad social corporativa analiza las condiciones y los incentivos que inducen a las empresas a la preocupación por los efectos de su comportamiento sobre el entorno social y ambiental (Salas, 2007, pp. 141-198).

${ }^{11}$ Hume (1739-1740, pp. 672-673) también se refiere a la reputación como fuerza que induce al respeto a la propiedad ajena. Pero parece pensar que solo en sociedades poco desarrolladas será suficiente la reputación, en los demás casos la acción del gobierno sería vital para asegurar los derechos de propiedad (Hume 1739-1740, pp. 717-720).

${ }^{12}$ Las relaciones entre personas darán lugar a vínculos fuertes -los que resultan del trato cotidiano con los familiares o compañeros de trabajo- y a vínculos débiles -los que son consecuencia de encuentros fortuitos con personas de otros ámbitos profesionales, ideológicos-. En los vínculos fuertes reposan las organizaciones que nutren cotidianamente a la sociedad de bienes, servicios e información del entorno inmediato; en los vínculos débiles la posibilidad de circulación de información y criterios entre los distintos ámbitos de las sociedades.
} 
duo el cambio en la recompensa neta esperada por obedecer o por desobedecer una norma. Descompone cada parámetro individual para diferenciar los cambios en la recompensa que se deben a fuentes internas al propio individuo -se siente mejor o peor consigo mismo por cumplir o incumplir- o externas - a consideración en que los demás le tienen se verá afectada por su comportamiento- ${ }^{13}$ Todo ello se realiza a su vez en un contexto en el que el grado de consenso sobre los distintos tipos de normas y reglas puede ser variado; en el que cada individuo pude tener su particular estructura de costes y recompensas internas y externas. Además, será un mundo con información imperfecta y desigual sobre cuál puede ser el comportamiento esperado de los otros cuando cada cual cumple o incumple las correspondientes normas. ${ }^{14}$ Nos presenta así Ostrom algunos de los elementos que permiten entender la dinámica institucional, especialmente si los combinamos con los posibles cambios en el contexto tecnológico o mercantil. Todo ello supone, desde mi punto de vista, un útil desarrollo y sistematización de los planteamientos de North (1990).

Pero además hay muchas potencialidades implícitas en la capacidad espontánea de la sociedad de fijar normas e inducir a su cumplimiento pues, al fin y al cabo, cumplir con las normas implica de hecho una preocupación por las repercusiones que nuestros actos puedan tener sobre los demás. Es decir, la producción de bienes públicos y el cuidado por los comunes pude ser también consecuencia de las actividades de las personas y empresas en contextos en los que los comportamientos que dañan a los otros (externalidades negativas) sean considerados inadecuados y por lo tanto deterioran la reputación de quien los realiza -incluso pueden deteriorar la imagen que uno tiene de sí mismo-, siendo sin embargo bien consideradas, y favorecedoras de una buena reputación, y de una buena conciencia, las actuaciones con consecuencias positivas sobre el entorno (externalidades positivas). De este modo, en un contexto adecuado, la dotación de bienes públicos y la preservación de los comunes mejorarán gracias a la atenuación de los comportamientos que puedan deteriorarlos y a la potenciación de aquellos qué los producen o sostienen. Las propias normas espontaneas pueden llevar implícito que tipo de bienes públicos o comunes son de especial relevancia y cómo es conveniente comportarse para producirlos y preservarlos.

De todos modos, y como señalaba Hayek, esta compleja interacción entre personas y organizaciones no solo implica la generación de normas y de condiciones para que los comportamientos se ajusten a ellas; en estas relaciones se mueve también información sobre experiencias, oportunidades y también ideas de todo tipo sobre aspectos religiosos, éticos, culturales, técnicos, científicos, mercantiles. ${ }^{15}$

De esta visión más compleja del modo de incidir de las instituciones sobre los comportamientos, North (2005) destaca las influencias derivadas de los instrumentos de pensamiento de los que van dotándose las sociedades. Las reflexiones individuales estarían condicionadas por los instrumentos de pensamiento que la sociedad va transfiriendo a sus miembros. Esta transmisión puede realizarse mediante sistemas educativos formalizados, de modo informal escuchando o leyendo las reflexiones de otros. A su vez, lo transmitido pueden ser tanto sistemas de pensamiento complejos de carácter científico, tecnológico o profesional, como sistemas de pensamiento menos elaborados, rutinas mentales incluso. Todo ello influye en los procesos de toma

\footnotetext{
${ }^{13} \mathrm{Al}$ tratar posteriormente de la acción colectiva y de la pública veremos cómo los costes de incumplir las normas se verán incrementados tanto por multas como por penas. En cualquier caso, para el correcto funcionamiento de una sociedad será clave que la moral y la reputación sean los principales inductores del cumplimiento de las normas para la inmensa mayoría de la población.

${ }^{14}$ Ostrom (2005, pp. 345-346) señala la posibilidad de establecer supuestos que simplifiquen y hagan manejable el análisis de situaciones concretas. Propone por ejemplo suponer cero algunos de los coeficientes o suponer iguales los de los distintos agentes. Conviene resaltar de todos modos que la impunidad -costes cero o muy bajo de incumplir las normas- puede ser un factor que dificulte gravemente la cooperación. Además, si la impunidad en el orden espontáneo es generalizada, será muy difícil que la coacción pública o de otros organismos la compense, entre otras cosas porque los agentes públicos gozarán también de amplia impunidad.

${ }^{15}$ Ostrom (2005, cap. V) también reflexiona sobre estas cuestiones.
} 
de decisiones y en el comportamiento. El lenguaje oral y escrito en sí mismo será un eficacísimo modo de sistematización y transmisión de criterios y modos de pensamiento generados formal o informalmente. El lenguaje es a su vez una magnífica muestra de cómo las actitudes y comportamientos van dejando en él su huella, influyendo así en las pautas de pensamiento y comportamiento de los nuevos integrantes de las sociedades.

Lo general de este planteamiento de North es que cualquier mente humana piensa sirviéndose de los resultados del pensamiento de otras. Las experiencias individuales son así analizadas por cada uno con los instrumentos conceptuales recibidos, y aunque en cada caso el manejo de este combinado de instrumentos y experiencias tenga sus peculiaridades personales -algunas pueden llegar a ser muy novedosas o excéntricas-, la capacidad de pensar, los modos de pensar y los objetos de pensamiento serán muy dependientes de la sociedad en las que se viva, condicionando a su vez el comportamiento (Henrich et al., 2001). Es decir, los modos de conocer, y el conocimiento en sí mismo son condicionantes evidente del comportamiento humano, como también lo son las experiencias y la información.

En este contexto de cómo la sociedad condiciona el comportamiento de quienes forman parte de ella se pueden incluir también las rutinas organizativas, mecánicas e intelectuales que se aprenden y se aplican en los distintos ámbitos de la sociedad y permiten una ágil y cotidiana viabilidad de los procesos de cooperación y producción (Hodgson, 1993). Pero conviene tener en cuenta que las rutinas, hábitos y normas disponibles en cualquier sociedad no necesariamente tendrán que ser las más eficaces para el logro de los objetivos deseados (Karlan y Apple, 2011, pp. 15-17).

\subsection{Las distintas caras de la acción colectiva}

La combinación de la acción individual con la colectiva da una visión de las sociedades en el que la persistente interacción entre agentes individuales, que provoca resultados agregados sobre los que aparentemente nadie tiene control, se combina con proyectos de grupos de individuos y organizaciones para dar respuesta a los problemas a los que colectivamente se enfrentan. Todo ello a su vez se ve entremezclado con la acción normativa, productiva y redistribuidora de las administraciones públicas. En los próximos párrafos se tratará de la acción colectiva y en el tercer epígrafe de la acción pública. Previamente debe quedar claro que la noción austriaca de orden espontáneo, a la que más arriba se ha hecho referencia, deja un estrecho margen a la acción pública y no incluye la acción colectiva, pues en una línea argumental muy similar a la que a continuación veremos en Olson, señala que el egoísmo de los grupos no tiende a potenciar, como el despliegue del individual -de personas o de empresas-, el interés general (Hayek, 1979 vol. III, pp. 158-165). ${ }^{16}$

Esta perspectiva crítica con la acción colectiva se ha visto posteriormente corregida por la línea de trabajo abierta por Ostrom (1990) y continuada por muchos otros investigadores. Trataremos sucesivamente de cada una de ellas, aunque la línea de fuerza que permite integrar la acción colectiva con la individual y la pública irá más en la dirección interpretativa de Ostrom que de Olson.

\section{Visiones críticas de la acción colectiva}

A lo largo de toda su trayectoria, Olson (1971, 1982 y 2000) fue muy crítico con las consecuencias de la acción colectiva y con las posibilidades de llevarla a cabo. Su enfoque se basaba en la reflexión de un individuo aislado que, a la vista de las distintas alternativas disponibles, elije con el objetivo de maximizar sus ingresos. Este modelo de comportamiento le permite a Olson explicar que los empresarios estén muy interesados en la producción de bienes privados (bienes individualmente apropiables), pues no cederán los bienes producidos hasta que quien los desee pague por ellos, recuperando así lo invertido y su correspondiente margen en el caso de que el

\footnotetext{
${ }^{16}$ Olson (2000, p. 84) sintetiza muy bien esta idea en el título de uno de sus capítulos "Individuos racionales y sociedades irracionales", es decir, solo ve coherencia entre objetivos y realizaciones en el ámbito de la acción individual para la producción de bienes privados.
} 
negocio vaya bien. Por lo tanto, la provisión de bienes privados se desarrollará correctamente en el ámbito del mercado y de las decisiones privadas.

Pero el mercado para su correcto funcionamiento necesita, según Olson (2000), una amplia dotación de bienes públicos y, al ser estos de libre acceso, los empresarios egoístas y racionales no estarán interesados en producirlos: el dinero que gasten para obtenerlos no podrán recuperarlo, pues como todos pueden disfrutar libremente de ellos nadie estará dispuesto a pagarles. ${ }^{17}$ Es decir, el individuo aislado y egoísta verá que su decisión más razonable es concentrarse en la producción y adquisición de bienes privados, disfrutando a su vez de los bienes públicos sin pagar por ello. En definitiva, el sistema de mercado será un buen proveedor de bienes privados pero un fatal suministrador de los bienes públicos que necesita para su correcto funcionamiento.

Pero los particulares y las empresas necesitan una gran variedad de bienes públicos. Seguridad pública, seguridad en el cumplimiento generalizado de las normas y contratos, respeto a los derechos individuales y colectivos y, además, calles limpias, bien mantenidas e iluminadas; redes de transporte urbanas e interurbanas. A todo el mundo le son muy provechosos también unos conciudadanos educados, respetuosos y capaces. Todo ello implica que estén sanos, bien formados y dispongan de oportunidades para utilizar sus capacidades ¿Quién no desea además una atmósfera limpia, agua no contaminada, unos alimentos no alterados en sus propiedades por la contaminación del suelo o el agua o por modos de producirlos peligrosos para la salud? También, otros bienes públicos más controvertidos, como la estabilidad económica general $-\mathrm{o}$ la personal de cada uno-; o la capacidad de una sociedad de desarrollar actividades de investigación, o líneas de producción complejas, cuyas sinergias abran nuevas oportunidades para todos, aunque sean poco atractivas para los inversores particulares.

Para el individuo aislado y egoísta de Olson su ideal, con los bienes públicos, sería vivir en una sociedad bien abastecida de todos ellos, disfrutarlos, pues cualquiera puede hacerlo, y por supuesto no pagando por ellos. El problema es que, si nadie está dispuesto a emplear su tiempo o su dinero en producir este tipo de bienes o en preservar su conservación, la sociedad sería un lugar poco agradable, en la que Olson (2000, p. 78), parafraseando a Hobbes, piensa que la vida sería "solitaria, pobre, desagradable, brutal y corta".

Prácticamente en la misma dirección argumenta Hardin (1968) refiriéndose a los bienes comunes. ${ }^{18}$ Destaca la incapacidad de los particulares por sí mismos para alcanzar y cumplir los acuerdos necesarios para evitar la sobreexplotación, y consiguiente degradación, de pastos u otros espacios comunes. Sitúa además este problema en el contexto general de la degradación de los comunes globales, como los mares o la atmósfera. Se puede añadir, completando esta línea argumental de Hardin, que casi a cualquier bien público le ocurriría lo mismo que a los comunes: irá perdiendo sus cualidades con un comportamiento inadecuado de los usuarios. Así, por ejemplo, la preservación de la confianza mutua, de las capacidades o la salud de la población, de la limpieza o la seguridad viaria, requieren un comportamiento cotidiano cuidadoso y comprometido de ciudadanos y organizaciones. ${ }^{19}$ La hipótesis de Olson y Hardin es que ese esfuerzo

\footnotetext{
${ }^{17}$ Evidentemente los empresarios particulares estarán interesados en producir bienes públicos si alguna administración pública les paga por este cometido. Cuando hay falta de oportunidades de inversión, este tipo de negocio suele estar muy solicitado (Nell, 1999, pp. 36-39)

${ }^{18}$ Sobre el concepto de lo común y su evolución véase Laval y Dardot (2015, pp. 27-61). Su propuesta de que "Lo común debe ser pensado como una co-actividad..." (Laval y Dardot, p. 57). Es decir, lo que hace comunes los recursos es la necesidad lograr combinar adecuadamente comportamientos individuales, colectivos y públicos para su sostenibilidad o producción. El concepto de lo común va así más allá de los recursos naturales pues las acciones individuales y colectivas pueden ir ligadas a preservarlos, pero también a potenciar otros bienes como la confianza, la formación o la seguridad pública.

${ }^{19}$ Creo que resulta necesaria una aclaración sobre el carácter mixto, es decir, de público y colectivo, de algunos recursos. El carácter de bien público de la condición confiable, saludable o capaz de una población se debe a que estas cualidades no implican rivalidad ni posibilidad de exclusión de sus usuarios: su uso cotidiano por unos y otros mejorará su dotación; además, todos se pueden beneficiar de un modo u otro de relacionarse con conciudadanos con esas características. Su carácter de bienes comunes se deriva de que su conservación depende de un comportamiento activo de todos los agentes si se quiere potenciar-
} 
sería difícil de sostener sin la coacción del Estado. ${ }^{20}$ La hipótesis opuesta, implícita en el concepto de orden espontaneo y en el de acción colectiva de Ostrom, es que los comportamientos respetuosos con bienes públicos y comunes serían inviables sin una sociedad con una elevada capacidad de autogobierno. Como veremos más adelante ambas perspectivas pueden ser complementarias.

De todos modos, pese a su visión negativa de las acciones colectivas, Olson se enfrenta a analizar la posibilidad de que los grupos de individuos con necesidades similares de bienes públicos -o de preservar bienes comunes- se organicen para autoabastecerse de ellos a través de las correspondientes acciones colectivas. Toma como ejemplo sindicatos de trabajadores que negocian mejores condiciones de trabajo, mayores salarios, vacaciones o formación; y organizaciones empresariales o profesionales - médicos, abogados-o de agricultores y ganaderos. Su conclusión es francamente pesimista: las acciones colectivas solo serán viables, e impulsoras estables de la producción de bienes públicos, en los grupos pequeños y en aquellos grandes que generen incentivos adecuados para animar a sus miembros a participar y pagar.

En los grupos pequeños la acción colectiva será viable gracias a la posibilidad de acuerdos estables entre los miembros del grupo: no habrá incentivos para salirse del acuerdo para producirlos, pues la falta de tu aportación afectará negativamente a la calidad del bien público del que se disfrutaría; habrá incentivos para sumarse a él pues la nueva aportación individual lo mejoraría. Idénticas deducciones, pero en sentido negativo, se señalan cuando el grupo es grande: la aportación individual, ni en el caso de que se retire o se agregue, afectará significativamente a la calidad del bien público. Es decir, desde la perspectiva del individuo egoísta miembro de un grupo grande no tiene sentido pagar para disfrutar del mismo bien público que si no pagase. Los que estaban inicialmente de acuerdo en cooperar para producirlo tenderán a salirse del acuerdo y los que estaban fuera no tendrán incentivos para incorporarse, por lo tanto, el grupo grande se quedará sin los correspondientes bienes públicos, pues nadie estará dispuesto a pagar lo que cuesta producirlos. $^{21}$

Solo en el caso de que los grupos grandes generen algún tipo de incentivos específicos será viable la acción colectiva. Por ejemplo, incentivos de carácter negativo: solo se beneficiarán de los acuerdos entre el sindicato y la empresa los trabajadores sindicados al corriente de sus obligaciones o pagos; si no estás asociado no puedes ejercer la profesión de médico, abogado, arquitecto. $\mathrm{O}$ de carácter positivo: si pagas las cuotas tendrás derecho a algún bien privado complementario al público -revistas, acceso a economatos o a seguros en condiciones especialmente favorables-.

El conjunto de acciones colectivas viables según Olson generaría una dotación de bienes públicos insuficiente e irregularmente repartidos. En las pequeñas urbanizaciones habría incentivo para proveerse de limpieza, iluminación, seguridad; en las grandes barriadas en las que los acuerdos para la provisión de bienes públicos serían complejos reinarían la oscuridad, la suciedad y la delincuencia. Algunas actividades laborales con incentivos selectivos para inducir a la acción colectiva estarían adecuadamente reguladas para los intereses de sus miembros. En otras los trabajadores estarían a merced de la prepotencia de sus empleadores. Diferencias similares en la capacidad de desarrollar acciones colectivas se darían entre las empresas según las caracte-

los o evitar su degradación: cada uno se debe cuidar de su salud, de su formación y de su comportamiento; su entorno social deberá inducirle a ello; los organismos, tanto los públicos como los privados, deberán cuidar de la promoción de estas cualidades. Algo similar ocurre con otros bienes mencionados en el texto como el sistema normativo formal o informal de una sociedad o la seguridad y la limpieza pública. Los conceptos de capital humano y capital social permiten ver más claramente este carácter mixto, como bienes públicos y comunes, de los bienes mencionados (Ostrom y Ahn, 2003, pp. 168-178). La calidad medioambiental sería más propiamente un recurso común a causa de su riesgo de degradación por un uso excesivo o inadecuado.

${ }^{20}$ En algunos casos particulares la alternativa también podría ser la privatización del bien colectivo (Coase, 1960).

${ }^{21}$ Como señala Olson (2000, pp. 96-102) el resultado señalado en el texto es válido incluso en ausencia de costes de transacción ya que siempre habrá costes de producción del bien público que no habrá incentivos para pagar. 
rísticas de su sector productivo, y entre los agentes implicados en el aprovechamiento de los distintos tipos de bienes colectivos.

Pero es que además el desarrollo de acciones colectivas genera organizaciones con capacidad de convertirse en grupos de presión. Estas organizaciones podrán actuar sobre los organismos públicos para inducir políticas fiscales, de gasto y de regulación que les resulten favorables, a costa probablemente de aquellos otros grupos que no reúnen las condiciones para organizar adecuadamente la defensa de sus intereses. Es decir, para Olson la acción colectiva no es el camino adecuado para que una sociedad se dote de bienes públicos. Su afloramiento es más bien un problema que una ventaja para el correcto funcionamiento de la sociedad. ${ }^{22}$

Si ni la acción privada ni la colectiva son adecuadas proveedoras de bienes públicos, la alternativa para Olson es el Estado que obligará coercitivamente a los ciudadanos a cumplir normas y a pagar impuestos para financiar la producción de los bienes públicos que la sociedad necesite. $^{23}$

\section{La acción colectiva recuperada}

Olson, como acabamos de ver, adopta unos supuestos conductuales de las personas que le permiten indagar sobre el problema de la provisión de bienes públicos en situaciones en las que los frenos morales son débiles y la preocupación por la reputación no existe o es muy reducida quizá por la falta de vínculos interpersonales o interempresariales que le den relevancia. $\mathrm{O}$ una interpretación alternativa: puede haber situaciones en las que, pese a existir valores morales y vínculos interpersonales que induzcan a cuidar de la reputación, no actúan por sí mismos con la intensidad requerida para inducir al cuidado de algunos tipos de bienes colectivos o a la financiación de la provisión de algunos bienes públicos. ${ }^{24}$

Pero claro, si introducimos los supuestos conductuales que nos sugiere Ostrom (2005, pp. $343-406)^{25}$ con el concepto de cooperadores condicionales, veremos que salirse de un acuerdo, no incorporarse a él o no cumplir lo acordado para poner en marcha una acción colectiva, podrá resultar costoso desde el punto de vista de la moral y de la reputación de cada cual. Si al mismo tiempo los organizadores de la acción colectiva introducen sistemas de vigilancia profesionalizados junto al control mutuo, así como sanciones especificas superpuestas al coste moral y en reputación, la viabilidad de la acción colectiva aumenta, particularmente si estas sanciones son también reconocidas por las administraciones públicas. En este contexto la acción colectiva sería viable, tanto entre empresas como entre particulares, y con ella se podría gestionar pastos, bosques, riegos, el acceso colectivo al mercado o a nuevas técnicas, o desarrollar establemente actividades de muy distinto tipo, ya sea de carácter formativo, deportivo, religioso, político.

En definitiva, desde la perspectiva de Ostrom la capacidad de autogobernanza de las sociedades se nutre también de las acciones colectivas, es decir de la capacidad de grupos de individuos, empresa o familias de organizarse para gestionar el acceso a algún bien colectivo, para la producción de bienes públicos o para la gestión de los posibles conflictos u oportunidades que puedan ir descubriendo.

La acción colectiva, además de solucionar los asuntos concretos para los que se organizó, puede modificar o condicionar el modo de comportamiento de personas y organizaciones transformándose así las normas informales que orientan el comportamiento, ${ }^{26}$ además de emitir nor-

\footnotetext{
${ }^{22}$ Esta idea se desarrolla particularmente en Olson (1982).

${ }^{23}$ Hume (1739-1740, pp. 713-719), siguiendo una línea argumental no muy distinta a la de Olson, alcanzó similares conclusiones respecto al papel del Estado en el suministro de bienes públicos.

${ }^{24}$ Becker (1976), para analizar el comportamiento humano en distintos ámbitos con el enfoque económico, utiliza unos supuestos de conducta de las personas del mismo tipo que los de Olson.

${ }^{25}$ Véase también Ostrom y Ahn (2003, pp. 178-199).

${ }^{26}$ Las acciones colectivas además de desplegar su efecto directo en el ámbito de que se trate -comercial, productivo- cohesionan a sus miembros mejorando su capacidad de negociación respecto a terceros. Los efectos sobre las normas informales son más evidentes si se trata de acciones colectivas con ese objetivo específico. Sería el caso de los movimientos feministas, LGBT, ecologistas o de minorías étnicas o culturales.
} 
mas formales que ordenarán aspectos específicos de las relaciones entre los cooperantes. Las acciones colectivas tenderán también a reforzar los vínculos entre las personas y las organizaciones de la sociedad en la que se desarrollan, mejorando así, gracias a la mayor interacción social, la importancia de la reputación como inductora de comportamientos respetuosos con las normas. Los vínculos débiles tenderán a ser más abundantes (Granovette, 1973). En este contexto la capacidad de producir bienes públicos y de cuidar de los comunes se verá considerablemente acrecentada gracias a la interacción virtuosa entre la acción individual y la colectiva. La fundación de nuevas empresas es probable que pueda llegar a tener un efecto muy similar al del desarrollo de acciones colectivas pese a que los vínculos entre los agentes en el interior de ellas tengan un carácter más jerárquico (Gallego, 2007, pp. 123-125).

Pero incluso esos comportamientos guiados por la reputación y los valores asumidos pueden tener graves efectos externos negativos si esos valores son racistas, clasistas, machistas o en general gravemente discriminatorios para algunos grupos sociales. Además, tanto la acción individual como la colectiva pueden generar inercias de largo plazo, con implicaciones sociales variadas y no siempre positivas, al inducir a interiorizar, como se ha visto, las normas que las ordenan o impulsan pese a que puedan estar muy alejadas de la ecuanimidad.

De todos modos, la imagen que nos trasmite Ostrom desde sus primeros trabajos (Ostrom 1990), hasta los más actuales (Ostrom, 2010), es la de una amplia posibilidad de desarrollar multitud de acciones colectivas en distintos ámbitos que nutrirán a la sociedad de bienes públicos y colectivos, completando a los provenientes del comportamiento y la interacción entre particulares propia del orden espontáneo.

Esta potencial amplitud de las acciones colectivas restaría vigor al problema señalado por Olson al indicar que a través de ella se producirían bienes públicos insuficientes e inadecuadamente distribuidos. Además, su efecto sobre las decisiones de las administraciones públicas podrían ir por otros caminos distintos a los señalados por Olson y positivos para la colectividad: una sociedad rica en acciones colectivas, es decir bien trabada organizativamente, tendrá más informado y más controlado a los distintos organismos públicos y, a su vez, los valores considerados con los otros tenderán a ser más generales condicionando el comportamiento de los particulares, empresas y también el de políticos y funcionarios. ${ }^{27}$

Pero las propuestas de Olson seguirán siendo una útil llamada de atención para recordar que en algunas circunstancias las acciones colectivas pueden producir efectos perversos sobre las administraciones públicas y también sobre otras acciones colectivas o sobre grupos de particulares no organizados. ${ }^{28}$ Ostrom era consciente de estos problemas. Con sus ocho principios nos muestran la necesaria reciprocidad, confianza y percepción de capacidad de autogobierno entre los cooperantes de cualquier acción colectiva para que esta perdure y haga perdurar el recurso administrado en el largo plazo. Indirectamente estos principios nos muestran a su vez que, cuando no se den o se den muy imperfectamente, las acciones colectivas pueden tener graves deficiencias tanto en su organización interna como en su relación con el resto de la sociedad. ${ }^{29}$ Pero ella insiste de todos modos en el enorme potencial de las acciones colectivas si su diseño y su contexto son adecuados, incluso señala la capacidad de corrección positiva de los contextos que podría derivarse de la reiteración de acciones colectivas, es decir, las acciones colectivas pueden acabar conduciendo a un orden espontáneo más equilibrado.

\footnotetext{
${ }^{27}$ En varios de sus últimos artículos, Beltrán (2013 y 2015) nos muestra las externalidades positivas derivadas de la gestión colectiva de los comunes. En concreto, identifica una incidencia positiva de estas acciones colectivas sobre la educación, la salud y también sobre el crecimiento (Beltrán, 2016).

${ }^{28}$ Un análisis de las circunstancias sociales (la persistente conflictividad principalmente) que pueden inducir a las externalidades negativas de unas acciones colectivas sobre otras puede encontrarse en el trabajo de Planas y Valls-Junyent (2011) sobre el cooperativismo agrícola en un municipio catalán.

${ }^{29}$ Ostrom para establecer sus ocho principios parte de la larga experiencia de éxitos de la acción colectiva organizada en muchas partes del mundo para la gestión del riego, pastos y bosques, las pesquerías u otros recursos naturales. Analizando las características de las organizaciones con éxito, extrae como común denominador ocho condiciones (Ostrom, 1990, pp. 88-102 y 2005, pp. 600-630). Para un análisis de los principios a través de los casos españoles manejados por la autora véase Garrido (2011). Un breve repaso a la reformulación de esos principios en Sanchis (2016, pp. 41-47).
} 
Además, Ostrom muestra la capacidad de concertación de unas acciones colectivas con otras para gestionar los dilemas comunes a grandes grupos humanos (octavo principio). Esta concertación puede conducir al anidamiento de varios organismos colectivos en una institución común. ${ }^{30}$ Pero claro, en la medida que estos anidamientos no tengan lugar o algunos grupos tengan más capacidad de ponerlos en marcha que otros, podrán reaparecer los problemas planteados por Olson y Hardin.

Hasta ahora se han analizado la capacidad de autogobierno de las sociedades, es decir, las normas informales y el conjunto de criterios éticos y morales y de instrumentos conceptuales que suponen probablemente, pese a su carácter inmaterial, el patrimonio más potente de cualquier sociedad. Hemos ido viendo cómo se constituye y modifica ese patrimonio en las relaciones sociales cotidianas propias del orden espontáneo y mediante las consecuencias de las acciones colectivas que despliegan los miembros de las sociedades. Además, esos comportamientos privados y colectivos hemos visto que potencialmente tienen una gran capacidad de dotar a la sociedad de una amplia diversidad de bienes públicos y comunes más allá de los que componen el patrimonio inmaterial al que se acaba de hacer referencia.

Indudablemente es necesario añadir a este panorama la acción pública, ya que a través de su actividad normativa el Estado completará el patrimonio inmaterial con las normas formales, con la capacidad de incidir sobre las informales y sobre los demás aspectos del patrimonio inmaterial. Todo ello se completará con la organización de distintos métodos de seguimiento y castigo de los comportamientos no respetuosos con las normas. Las políticas públicas de ingresos y gastos serán a su vez el soporte de la provisión de una gran diversidad de bienes públicos complementarios o sustitutivos de los generados desde la sociedad civil por individuos y grupos.

Pero antes de entrar en el análisis de la acción pública conviene hacer algunas precisiones que, aunque evidentes, creo que resultan necesarias. El interés y la potencia analítica de las propuestas de Elinor Ostrom sobre la acción colectiva no deben inducir a retirar del campo de observación las fuerzas cotidianas del orden espontáneo; quizás en esas relaciones privadas entre particulares estén las principales claves para entender la evolución de las sociedades. Tampoco creo que deban olvidarse las perspectivas críticas sobre la acción colectiva que nos transmiten Hayek y Olson, pues pueden darse situaciones en las que la capacidad de los distintos grupos de intereses de poner en marcha acciones colectivas sea muy desigual y, en ese caso, a las desigualdades individuales en el acceso a los recursos se añadirían las derivadas de la capacidad diferencial de nutrirse de bienes públicos y de influir en las decisiones de las administraciones públicas.

Tampoco creo que deba perderse de vista la complejidad de la producción de algunos bienes públicos desde la acción individual o colectiva ya sea por las razones Olson (posibilidad de gorroneo), por sus elevados costes de transacción a los que se refería Coase (1960) o por las economías de escala implícitas en la organización de su producción (North, 1981). ${ }^{31}$ También hay que considerar la complejidad de la gestión de los comunes globales (Hardin, 1968), para la cual sería conveniente tanto la combinación de acciones individuales, colectivas y públicas, como la acción colectiva entre los distintos estados del mundo. Quizá uno de los retos de la sociedad actual sea llegar a tener tanto éxito en la gestión de los comunes globales como tuvieron muchas comunidades rurales en la gestión de sus comunes, haciendo compatible su aprovechamiento con su preservación.

En definitiva, lo que si se deduce del análisis de la capacidad de autogobierno de las sociedades, es que una buena dotación de bienes públicos y comunes sería inviable sin que la acción de las administraciones públicas se complete y se asegure con las acciones individuales y colectivas de individuos y organizaciones. Desde el punto de vista de la política económica será por lo

\footnotetext{
${ }^{30}$ En Lana y Laborda (2013) puede encontrarse un interesante análisis general del concepto de anidamiento, así como su aplicación a dos comarcas navarras. Un ejemplo de los problemas del anidamiento en Sanchis (2016).

${ }^{31}$ También se refiere Ostrom (2005, pp. 651-664) a la existencia de bienes públicos difíciles de ser producidos mediante la acción colectiva debido a las economías de escala a las que se refiere North.
} 
tanto clave no solo no obstruir sino también fomentar y equilibrara las capacidades de autogobierno, con ello se reforzarán a su vez las libertades públicas y, consiguientemente, la democracia, y también la eficacia del Estado como organización.

\section{La acción pública}

Los estados han desarrollado actividades muy relevantes en la construcción y modificación del patrimonio inmaterial de las sociedades, así como en el de la producción de una gran diversidad de bienes públicos. El objetivo de este epígrafe es presentar los instrumentos que nos brinda la economía institucional para analizar el comportamiento del Estado en ambos aspectos. Con ellos podremos evaluar a su vez qué elementos condicionan las características de los Estados y su acción pública.

Vamos a tratar del Estado desde tres puntos de vista: como organización con sus propias inercias y con un gran margen de autonomía respecto a la sociedad sobre la que ejerce la soberanía (Hayek, 1944; Mises, 1947 y Jasay 1985); el Estado como organización al servicio de quienes lo controlan (Olson, 2000). Esta perspectiva se completará con el análisis de los modos de hacerse con el control del Estado (Acemoglu y Robinson, 2006) y por fin se observará al Estado como organización profundamente condicionada por las características de la sociedad sobre la que gobierna (North, 1990; Coase, 1937 y Ostrom, 2005). Probablemente cualquier Estado concreto tenga rasgos de cada uno de estos tres prototipos, pero también es cierto que los distintos estados históricos probablemente se hayan caracterizado por combinar en distintas proporciones cada una de estas facetas. Por ello he optado por presentarlas sucesivamente intentando entrelazarlas entre sí y con los otros aspectos de las sociedades que se han visto en los epígrafes anteriores.

En todas estas perspectivas las características del Estado y de la acción pública se van a ver muy condicionada también por el tipo de sistema político a través del cual se gestiona el Estado y se relaciona con el resto de la sociedad. Desde el punto de vista de las teorías de las formas de gobierno el sistema político condicionará las relaciones entre los distintos órganos del Estado y el grado y el modo en el que están representados en él, o pueden incidir en las decisiones públicas, los distintos grupos sociales, ${ }^{32}$ este asunto lo trataremos especialmente en el sub-epígrafe 3.

\subsection{De la autonomía del Estado y de sus riesgos.}

La primera perspectiva comentada ve al Estado como una organización con elevado grado de autonomía respecto al resto de la sociedad. Se supone que el Estado dejado a su propia lógica parece tener inercias que le inducirían a absorber al resto de la sociedad desarrollando, en la culminación de ese camino, tendencias totalitarias. En las fases intermedias ha podido propiciar la democracia y la movilización ciudadana ante objetivos que podían ayudar a la ampliación de sus competencias. Este miedo a que el Estado se acabase tragando a la sociedad y disolviendo la vitalidad del capitalismo se basaba en la observación de las experiencias fascistas y nacionalsocialista y en las de la formación de la URSS y los demás estados comunistas. Pero también en el progresivo intervencionismo en la economía de los gobiernos de los países desarrollados que cobró nuevo ritmo desde comienzos del siglo XX y, sobre todo, en las décadas de fuerte expansión que siguieron a la Segunda Guerra Mundial.

En una de las versiones más extremas de este planteamiento (Jasay, 1985) se llegan a interpretar las ideologías redistributivas de la renta entre personas y territorios, o las de discriminación positiva por motivos de raza o género, como ideologías promovidas por el Estado al propiciar con el desarrollo de esas políticas el aumento de sus competencias y poder social. ${ }^{33}$ Mediante estas intervenciones el Estado irá sustituyendo los equilibrios sociales derivados de la interacción entre los deseos y comportamientos de todos, propios del orden espontáneo, por las decisiones autoritarias de unos pocos. El Estado intentará ampliar sus tentáculos planificando la vida social y, por supuesto, la economía de mercado.

\footnotetext{
${ }^{32}$ Recomiendo encarecidamente la lectura de la breve historia del pensamiento político de Bobbio (1976).

${ }^{33}$ Ideas similares pueden encontrase en Hayek (1976 vol. II, pp. 128-136)
} 
Una síntesis y un precedente brillante de esta línea argumental la encontramos en un pequeño texto de Mises (1947) y en un famoso trabajo de Hayek (1944). En ambos vemos que el miedo principal es la paulatina sustitución del mercado por la intervención y la planificación. Nos muestran al sistema de mercado como una democracia en la que a través del gasto de sus ingresos los consumidores votan qué quieren que se produzca. Es decir, los consumidores deciden democráticamente cómo quieren que se usen los recursos disponibles. El voto puede parecer desigual, pues unos tienen más capacidad de gasto que otros, pero eso se debería a que los más ricos han sabido como profesionales o empresarios adaptarse mejor a los deseos de los consumidores; por lo tanto, sus mayores ingresos no dañan, sino que perfeccionan el funcionamiento de la democracia económica. ${ }^{34}$ Controlando a través de la intervención del Estado la producción y los precios se estarían sustituyendo los criterios colectivos democráticamente expresados mediante decisiones de compra, por la decisión de unos pocos burócratas. Se drenará así a los consumidores libertad de elegir, y se desincentivará a empresas y profesionales a servirles mejor.

El asunto es cómo frenar a una organización tan peligrosa, pero al mismo tiempo tan necesaria para asegurar la paz, la libertad y la justicia, es decir, para asegurar el carácter espontáneo del orden social evitando la violencia privada, la intromisión de unos, y del propio Estado, en la decisiones de otros, evitando a su vez las normas discriminatorias que favorezcan a unos a costa de otros. El problema es que el poder acumulado por los Estados, incluidos los democráticos, les puede permitir ampliar sus competencias mucho más allá de estos límites. Además, los procesos de negociación a través de los cuales se tejen las mayorías parlamentarias en los sistemas democráticos dan juego y capacidad de influencia a los grupos de presión. Se tenderán a promulgar así leyes discriminatorias favorecedoras de algunos de ellos, ya sean representantes de sectores productivos, de territorios, de grupos sociales o étnicos. Es decir, cada uno de ellos intentará conseguir vía Estado lo que no han podido conseguir vía mercado o en general vía orden espontáneo. El Estado, al participar en este juego entre grupos de presión, aumentará sus competencias. ${ }^{35}$ Esta línea argumental del pensamiento austriaco es heredera de la tradición conservadora que se forjo frente a los cambios promovidos por el proceso revolucionario francés (Burke, 1790, pp. 73-79)

El riesgo de trastocar el orden espontáneo parece evidente en los sistemas políticos autoritarios, pero en los democráticos el poder omnímodo de los parlamentos tendería a producir también un choque entre la libertad individual y la libertad parlamentaria. La propuesta de Hayek (1979 volumen III, pp. 185-218) es clara: hay que frenar constitucionalmente las competencias de los parlamentos que eligen y controlan a los gobiernos. El objetivo sería que los gobiernos y los parlamentos que los controlasen estuvieran sometidos, como los ciudadanos, a las normas morales generales -a los criterios surgidos en el orden espontáneo-, evitando así su intromisión en los derechos individuales. Para ello propone un complejo sistema político -que es una versión reforzada de las limitaciones a los procesos legislativos del sistema político estadounidense- que se justificaría por el fracaso de las meras constituciones en la limitación de la acción pública y en particular la de carácter redistributivo.

Este miedo al crecimiento del Estado lo comparte la escuela austriaca con los fundadores de la teoría de la elección pública (Buchanan y Trullock, 1962). Estos últimos, para analizar las causas de la expansión del Estado y los modos de embridarlas, se embarcan en un análisis sistemático de los procesos de toma de decisiones públicas. Para ello consideran también de hecho al Estado como una organización con su propia dinámica -inducida por los interés individúales de políticos y burócratas- pero condicionada desde fuera por los votantes y por los grupos de presión. El resultado global de la interacción entre los intereses individuales de todos estos agentes -votantes, políticos, funcionarios, grupos de presión- estará condicionado por las carac-

\footnotetext{
${ }^{34}$ La dirección por el consumidor de los procesos de asignación de recursos en las economías de mercado quedaría considerablemente matizada si consideramos que estos eligen entre los productos que llegan al mercado como resultado de las decisiones de inversión de los empresarios.

${ }^{35}$ Para lo comentado en este sub-epígrafe véase Hayek (1979 vol. III y particularmente los caps. XII y $\mathrm{XVI})$.
} 
terísticas del sistema político en el que se desenvuelvan. Buchanan y Trullock se centran también en el análisis de las consecuencias de los distintos sistemas políticos democráticos y en el de las reglas para seleccionar uno u otro en el proceso constituyente. ${ }^{36}$

\subsection{El Estado al servicio de quienes lo controlan}

En el segundo enfoque se considera al Estado como una organización al servicio de quien la controle. Olson (2000, pp. 1-55) pretende explicar las razones por las cuales quienes controlan el Estado, guiados por una mano invisible -la izquierda según él-, se preocupan por que los impuestos no sean excesivos y también por la paz social, los derechos de propiedad y, en general, por la producción de una amplia diversidad de bienes públicos. A través de este análisis del Estado, Olson dará solución al problema de la incapacidad de los particulares y de sus acciones colectivas para generar una producción adecuada de bienes públicos.

Pero realmente en la argumentación de Olson prácticamente no se habla del Estado ni de los políticos o funcionarios. Solo trata de aquellos que lo controlan, sean reyes, tiranos o mayorías sociales en el caso de los sistemas democráticos. Este desinterés de Olson por estudiar el Estado como organización implica suponer que, para entender las fuerzas que conducen la acción pública, es un supuesto razonable pensar que el Estado como tal no tiene objetivos propios, sino que asume los de quienes lo controlan. La subordinación del Estados a los intereses de quienes lo controlan parece implicar a su vez que los políticos y funcionarios prosperarán si se comportan coherentemente con los intereses de los controladores de lo público.

Analiza Olson a quien controla el Estado, sea individuo o grupo, con la misma lógica egoísta racional empleada para el análisis del comportamiento individual al tratar de la acción colectiva. El objetivo del tirano, o de la mayoría en el caso de un sistema democrático, será maximizar sus ingresos netos derivados del control del Estado. Con esta finalidad le interesaría imponer una presión fiscal compatible con el normal desenvolviendo de la actividad económica privada, ya que el aumento desmedido de la presión impositiva, al poder afectar negativamente al nivel de renta de la sociedad, pude llegar a reducir los ingresos impositivos especialmente en el medio y largo plazo. Además, desde los intereses egoístas de quien controle el Estado, sería también razonable emplear parte de lo ingresado vía impuestos en financiar la producción de bienes públicos pues, con estos bienes, aumentaría la capacidad productiva de la sociedad y su capacidad futura de pagar impuestos. En definitiva, Olson nos señala que quien controla el Estado, aunque sea un déspota, tiene intereses inclusivos con el resto de la sociedad pues, al intentar maximizar sus ingresos, logra mejorar también las capacidades de los ciudadanos: los impuestos pagados serían inferiores al incremento de la renta inducido por los bienes públicos suministrados, y ello pese a que parte de los impuestos fueran al bolsillo privado de quien controlase al Estado. También se plantea el caso de que estas filtraciones netas sean excesivas y provoquen pérdidas netas a la sociedad.

En cualquier caso, este carácter inclusivo será más o menos intenso, y más o menos seguro, dependiendo del sistema político, es decir, de los modos de acceder y mantenerse en el poder de quien controle el Estado. En los sistemas autoritarios, sean monarquías absolutas o dictaduras modernas, una parte de lo ingresado por vía impuestos no será destinada a financiar bienes públicos, sino que se lo quedará el déspota para sus propios fines individuales. Para reforzar este argumento Olson supone que reyes y déspotas solo tendrán ingresos vía control del Estado. En algunos casos la fuerza de sus intereses particulares -intereses territoriales dinásticos fuera del país, por ejemplo- podrá orientarles a romper con sus intereses inclusivos con el resto de la sociedad. Olson recurre para aclarar su idea a los casos de Felipe II y de Luis XIV.

En una democracia gobernada por una mayoría social los incentivos para desviar ingresos fiscales hacia ella serán menores, pues las mayorías tienen ingresos por dos caminos, como controladoras del Estado y como particulares que desarrollan sus peculiares actividades de mer-

\footnotetext{
${ }^{36}$ La riqueza temática de la teoría de la elección pública puede apreciarse en el enciclopédico trabajo de Mueller (2003). El camino recorrido puede evaluarse comparando la diversidad temática y metodológica que refleja la recopilación de Mueller con el texto casi fundacional de Tullock (1976) que combina el encanto de su brevedad y claridad con el de su persistente actualidad.
} 
cado. Así, el incremento de los impuestos, o su uso para la producción de bienes públicos, les afectará a las mayorías por dos caminos. Como particulares les perjudican los impuestos y les beneficia la mejor provisión de bienes públicos, y como controladores del Estado les podría beneficiar la redistribución neta de hacia ellos de parte de los ingresos fiscales. En el caso de que la mayoría fuera superinclusiva dicha redistribución neta tendería a ser nula.

Las mayorías superinclusivas se caracterizarían por tener una profunda comunidad de intereses en el ámbito del mercado con el resto de la sociedad, de tal modo que lo que puede perjudicar a las minorías, vía aumento de impuestos o inadecuada dotación de bienes públicos, les acabaría perjudicando indirectamente a las mayorías. Así pues, a las mayorías, pese a controlar el Estado, sus intereses les conducirán a maximizar sus ingresos solo mediante los que obtienen vía mercado. Para lograr este objetivo lo recaudado se emplearía tan solo en la financiación de bienes públicos. En este contexto la magnitud de los impuestos dependería del gasto necesario para financiar la producción de los bienes públicos demandados por la sociedad, sin que se desviara dinero al bolsillo de nadie. El equilibrio implicaría que el último euro ingresado vía impuestos tuviese un efecto negativo sobre la renta igual al positivo generado por el bien público que financiara.

El resultado de esta argumentación es que las democracias son mucho más eficaces que las dictaduras en la gestión del Estado, pues en las democracias todos los ingresos fiscales tenderían a dedicarse a la financiación de los bienes públicos que la sociedad demandase, sin filtraciones hacia los bolsillos de nadie. Pero también será posible el crecimiento en el ámbito de los sistemas políticos autoritarios, aunque los gastos principescos -sobre todo los derivados de ambiciones territoriales exteriores- podrían acabar teniendo graves consecuencias.

La visión negativa de la acción colectiva que hemos visto en Olson -quienes la organizan tienden además a convertirse en grupos de presión- resulta muy coherente con su visión de los determinantes de la acción pública. Es decir, en un sistema democrático solo en ausencia de grupos de presión los políticos tendrían incentivos claros para poner en práctica las políticas superinclusivas de las mayorías sociales. Pero Olson piensa que las desviaciones de las políticas eficientes inducidas por los grupos de presión tienden a ser frecuentes y relevantes al combinarse con el problema de la relación de agencia del político respecto al votante -el principal, el votante, tiene graves dificultades de conocer las decisiones del político-. En este contexto de ignorancia parcial del votante, los grupos de presión pueden tener un margen relevante para la defensa de sus intereses particulares, desviando así a los políticos de las políticas eficientes a las que les inducían las mayorías superinclusivas. ${ }^{37}$ En Auge y decadencia de las naciones (Olson, 1982) se analizan las posibles consecuencias negativas de los grupos de presión sobre el desarrollo económico.

Da la impresión de todos modos que para Olson, en las democracias gobernadas por mayoría superinclusivas y sin grupos de presión que las distorsionen, la política se convierte en un problema técnico de elección de las políticas impositivas, de gastos y de regulación socialmente más eficaces, ${ }^{38}$ así como los niveles de descentralización más adecuados para gestionar cada uno de estos asuntos. Con el Estado democrático proveyendo de bienes públicos y el mercado, mediante la iniciativa individual, de los privados, no haría falta más; cualquier adición de acción colectiva sería contraproducente. ${ }^{39}$ Tras estas ideas de Olson están quizá la larga persistencia entre los economistas de las dos únicas opciones para solucionar los problemas de asignación de recursos: el mercado y el Estado (Ostrom, 2010).

\footnotetext{
${ }^{37}$ El carácter no homogéneo de las mayorías sociales puede ser un problema adicional para su control del Estado a través de la intermediación de los partidos.

${ }^{38}$ Esta es también la perspectiva que encontramos en Becker (1968). En concreto propones la selección de un sistema de penas y multas, y de un entramado policial y judicial que lo gestione, con el objetivo de optimizar los resultados. Esto implicaría diferenciar normas y graduar penas y multas en función del tipo de delito y las características de los delincuentes. La teoría de la elección pública también orienta sus propuestas en esta dirección de diseños institucionales que induzcan a resultados óptimos del comportamiento agregado de los agentes políticos.

${ }^{39}$ A la acción individual como proveedora de normas y otros bienes públicos ni la menciona Olson.
} 


\subsection{La conquista del Estado y la construcción de los sistemas políticos}

Puede ser útil combinar las propuestas de Olson (2000) con las de Acemoglu y Robinson (2006) cuando tratan de "los orígenes económicos de las dictaduras y las democracias". ${ }^{40}$ Acemoglu y Robinson ven a la sociedad formada por dos grupos con intereses distintos -la élite y los ciudadanos-, aunque su argumentación puede adaptarse perfectamente a una mayor complejidad social. Cada grupo pretende utilizar el poder político para sus propios fines, y el Estado como organización parece que resulta una maquinaria manejable para quienes lo controlen. Se aprecian pues similitudes con los planteamientos de Olson, pero como veremos su argumentación tiene un mayor contenido político.

Cada grupo tendrá sus peculiares capacidades de negociación política derivadas del poder de derecho que le otorga el sistema político y del poder de hecho, derivado este último de su capacidad de movilización o de influir por caminos no estrictamente legales en las decisiones públicas. En esta relación entre las distintas fuerzas sociales cada una de ellas, al diseñar sus estrategias, tiende a hacerse una idea hipotética de las de sus oponentes, así como de los posibles resultados de la interacción entre ambas. En este contexto toman sus decisiones de acción política, que también se verán influidas por las previsibles consecuencias de las coyunturas económicas en las posibilidades de ambos contendientes.

Incluyen Acemoglu y Robinson en su argumentación la posibilidad de que ambos grupos en conflicto den solución, de modo más o menos eficaz, a los problemas de organización de las acciones colectivas necesarias para poner en marcha sus estrategias políticas. En estas negociaciones y enfrentamientos estratégicos se irá conformando el sistema político que, sea democrático o no democrático, en cada caso irá alcanzando sus peculiares perfiles derivados del proceso que condujo a su constitución.

Esta división de los sistemas políticos en democráticos y no democráticos es una simplificación funcional inicial que luego se irá complicado. Pero en síntesis los sistemas no democráticos se caracterizarían por excluir del acceso al poder de derecho a algunos grupos sociales. En ausencia de revoluciones, las élites serían las que controlarían el poder formal vedando a los demás ciudadanos el acceso a él. A los excluidos solo les quedaría el poder de hecho para influir en las decisiones políticas o para intentar modificar el sistema político. En la democracia el acceso al poder político sería general, al menos mediante el voto y las libertades públicas. En ellas los intereses de los ciudadanos, es decir, de la mayoría de la población, se verían mucho mejor representados que en las no democracias ya que las élites tendrían menos margen de maniobra para poner en práctica sus políticas. El margen de maniobra concreto de unos y otros dependería de todos modos de las peculiaridades del sistema político que hubiesen pactado.

Pero ¿para qué quieren los distintos grupos sociales acceder al control del Estado? Así como Olson centra su análisis de la política y del Estado en las consecuencias sobre la provisión de bienes públicos de quién y cómo controla el Estado, Acemoglu y Robinson destacan los objetivos redistributivos entre grupos sociales como el principal móvil de los interesados en controlar al Estado. Da la impresión que en la perspectiva de estos autores el Estado es una máquina que redistribuye rentas a favor de los grupos que lo controlan.

En los sistemas no democráticos, en los que el Estado estaría controlado por la élite, la presión impositiva sería previsiblemente baja y la actividad redistributiva hacia los ciudadanos muy limitada. En las democracias la presión impositiva sería elevada y el efecto redistributivo en contra de la élite también alto. Cabrían muchas situaciones intermedias en ambos tipos de sistemas políticos como resultado de los correspondientes procesos negociadores. En cualquier

\footnotetext{
${ }^{40}$ Me he ayudado en esta síntesis del trabajo de North (1981, pp. 35-48) "Una teoría neoclásica del Estado". En él se presenta un Estado en el que sus controladores tienen fines egoístas de acumulación que se sostienen a cambio de la oferta de bienes públicos a los ciudadanos -derechos de propiedad básicamente-. Incorpora también el conflicto entre los sectores sociales que se relaciona con el Estado. En general, las propuestas de Olson, Acemoglu y Robinson combinadas creo que mejoran las de North, excepto en la incorporación de las economías de escala como causa de la ventaja del Estado en la producción de algunos tipos de bienes públicos.
} 
caso, a los bienes públicos ni se les menciona, el papel nuclear del Estado como herramienta en manos de los grupos sociales parece ser ya la redistribución, ya intentar evitarla.

Creo que es interesante ir a una síntesis de las propuestas de Olson, Acemoglu y Robinson. Los tres sostienen que los objetivos de los agentes son egoístas, y que la acción pública se explica principalmente a través de los objetivos de quienes controlan el Estado. Olson propone que los sistemas autoritarios son unipersonales mientras que en las democracias gobiernan los grupos, las mayorías sociales. Creo que es útil decantarse por el supuesto de Acemoglu y Robinson de que tanto en las democracias como en las no democracias gobiernan los grupos sociales a través de los partidos políticos u otras organizaciones. Esto implica que en todos los sistemas políticos quienes los controlan actúan tanto a través del Estado como del mercado, usando el Estado no solo para acumular a través de él, sino también, como señala Olson para el caso de las mayorías, para mejorar según su criterio el funcionamiento de la economía de mercado a través de la producción de algún conjunto de bienes públicos.

Este doble papel del Estado facilitará a su vez las posibilidades de acuerdo, pues todos los grupos sociales tienen, en el lenguaje de Olson, algún tipo de interés inclusivo con los demás y con el conjunto de la sociedad. No solo hay pues problemas distributivos en los que la agregación de preferencias es tan complicada, sino problemas de elección de bienes públicos donde el campo de consenso puede ser mucho más amplio, particularmente si se conviene que a través de la redistribución se puede producir bienes públicos que mejoren las capacidades de los agentes económicos y del conjunto de la sociedad. En este sentido, combinando las deducciones de los tres autores considerados, en las sociedades democráticas tendería a haber mayor presión fiscal orientada a financiar una mayor producción de bienes públicos. El efecto redistributivo podría ser consecuencia del tipo de bienes públicos producidos, por ejemplo, del mayor peso en las democracias de los gastos en sanidad, educación o en la estabilidad económica personal.

Además, la perspectiva de Acemoglu y Robinson muestra al sistema político y al Estado como resultado de las acciones colectivas complejas de los grupos sociales en conflicto, lo que nos conduce a que los resultados, tipo de sistema político, tipo de Estado y de políticas, serán muy dependientes de las características de la sociedad -localización, orientaciones productivas, apertura exterior, niveles de desigualdad, relevancia de las clases medias- ${ }^{41}$ Con esta idea podemos pasar a la tercera perspectiva en la que se verá a la acción pública como muy dependiente del tipo de sociedad sobre la que el Estado actúe.

\subsection{El Estado condicionado por la sociedad}

North (1990) no presenta propiamente una propuesta sobre la acción pública pero, al tratar del cambio institucional y su dependencia de las inercias sociales, argumenta sobre la relación entre los valores de la sociedad y las características de sus organizaciones, considerando como tales desde cualquier tipo de empresa o asociación, hasta las administraciones públicas. Es decir, él indica que las organizaciones se constituyen siguiendo los incentivos y las limitaciones que contienen las normas sociales. Una vez constituidas su viabilidad futura dependerá de la continuidad de las normas o de su adaptación a las nuevas contingencias a las que se vayan enfrentando tanto el Estado como las otras organizaciones. Además, los individuos que las gestionan u operan en ellas estarán también formados y habituados a los criterios básicos que rijan en esa sociedad y, por lo tanto, no solo en su vida privada sino también en su actividad profesional tenderán a actuar de modo coherente con esos incentivos y limitaciones. Incluso la formación intelectual de funcionarios y políticos estará ligada al contexto social en el que se han formado y

\footnotetext{
${ }^{41}$ En este contexto de negociación de los rasgos concretos del sistema político entre los distintos grupos en conflicto, los investigadores en elección pública, o los politólogos influidos por esta u otras corrientes, o los especialistas en económica del comportamiento o en teoría de juegos, o aquellos orientados al estudio de las acciones colectivas, tendrían el papel de asesorar a las partes en conflicto sobre el modelo de sistema político que podría ser más adecuado a sus respectivos objetivos o, en su caso, sobre el camino a seguir para acordarlo. Estos asesoramientos afectarían posiblemente al contenido de lo acordado.
} 
actúan profesionalmente, lo que afectará a los instrumentos intelectuales que utilizan para reflexionar y tomar decisiones (North, 2005).

Es decir, la acción pública será muy dependiente de las normas y modos de pensamiento que rijan en esa sociedad. Podrán inducir según los casos ya a comportamientos discriminatorios, ya respetuosos con los intereses de los distintos agentes; podrán implicar comportamientos previsibles o con alto grado de aleatoriedad. Todo ello condicionará profundamente el papel del Estado. Incluso con sistemas políticos aparentemente similares, la acción pública tomará sendas muy diferenciadas dependiendo de las normas, valores éticos y morales e instrumentos de pensamiento dominantes. En fin, los agentes públicos, como los demás, serán también morales, sociales y egoístas al modo que sea habitual en su sociedad y en su ambiente. Todo ello influirá en su comportamiento al igual que su formación y sus experiencias.

Las normas sociales, los criterios, los modos de pensar condicionarán a su vez los objetivos de la sociedad, entre ellos los grados de solidaridad interclasista, intergeneracional o interterritorial, así como la preocupación por la seguridad, la formación, la investigación o el medio ambiente. Todo ello a su vez influirá en la relevancia otorgada a los distintos tipos de bienes públicos o colectivos. Estos bienes se suministrarán además en distinta proporción, según sea el tipo de sociedad, vía acción individual, colectiva o pública. El contenido y las formas de la acción pública estará pues condicionado por diversos caminos por los distintos componentes del entramado institucional de las sociedades.

Centrándonos en la acción colectiva vemos otros caminos a través de los cuales la sociedad condiciona la acción pública. Combinando las propuestas de Ostrom y Ahn (2003) con las de Olson (1982) vemos que la acción colectiva informa a las administraciones públicas de las peculiares necesidades de los grupos que las ponen en marcha; controla la acción pública al prever y luego seguir aquellas de sus decisiones que pueden afectarle; y por último, presiona a las administraciones públicas en el sentido de intentar mejorar a costa de otros como nos indicaban tanto Olson como Hayek. Es decir, la densidad de acciones colectivas y su distribución por sectores, grupos sociales y territorios es un fuerte vínculo a través del cual la sociedad condiciona a los distintos órganos del Estado, entendido este último como una organización compuesta por multitud de organismos con amplios grados de autonomía de unos respecto a los otros, y que a su vez se desenvuelven en contextos sociales, sectoriales o territoriales diferentes.

Indudablemente las presiones sobre los organismos públicos de las acciones colectivas pueden ir tanto en el sentido de mejorar las capacidades de todos, como en la de potenciar los aspectos extractivos (Acemoglu y Robinson, 2012, pp. 91-120) de las administraciones públicas hacia sí mismas, hacia las élites o hacia otros grupos. Lógicamente la acción individual también incidirá en la pública, ya mediante su influencia descentralizada en los distintos ámbitos sociales propia del orden espontáneo, ya por la presencia de agentes que alcancen una relevancia económica de grandes dimensiones. Esta incidencia, lógicamente, no tendrá que ser necesariamente positiva. En un régimen de libertades públicas la diversidad y representatividad de las acciones individuales y colectivas tenderá a ser mayor, y con ello los contrapesos que unas supongan para las otras podrán favorecer una acción pública más considerada con los intereses de todos.

Desde la perspectiva de Ostrom se genera también una teoría normativa sobre el comportamiento del sector público respecto a las acciones colectivas, que tiene similitudes con la desarrollada por Hayek para el caso del orden espontáneo. Ostrom indica cómo los organizadores de las acciones colectivas -gestión de riegos, montes, pesquerías o, ampliando su línea argumental, acciones colectivas de grupos de empresas con objetivos diversos: innovación, exportación, formación- conocen las peculiares necesidades de los agentes afectados, el tipo de relaciones existentes entre ellos, así como las características concretas del sector, del recurso gestionado y de otros aspectos significativos para la toma de decisiones. Por ello Ostrom (2005, pp. 509-565) señala que las reglamentaciones concretas seleccionadas por cada grupo de usuarios para autogobernarse - entre la enorme posibilidad de alternativas disponible- suelen estar adaptadas a todas esas circunstancias particulares. Puede haber por lo tanto un grave riesgo, viene a decirnos Ostrom casi parafraseando a Hayek, si las reglamentaciones públicas sustituyen a las seleccionadas por los particulares. Los perjuicios podrían llegar a ser importantes para los agentes implicados y para la conservación o producción del recurso afectado. 
Pero las soluciones a este problema propuestas por Ostrom van por un camino muy distinto al de Hayek. Mientras que este, como se ha visto en páginas anteriores, propone profundas reformas de los sistemas políticos para limitar la libertad de acción de gobiernos y parlamentos, Ostrom (2005, pp. 647-651) sugiere modificar los criterios de formación y comportamiento de investigadores sociales, funcionarios y políticos, para permitirles valorar mejor tanto las capacidades de autogobierno de los agentes particulares, como las limitaciones e ineficiencias de las reglas generales impuestas desde arriba. Este cambio de criterios favorecerá la selección de líneas de acción pública más eficaces para potenciar y completar las actividades colectivas. Es decir, la cooperación entre las acciones colectivas y la acción pública-local o estatal- puede dar magníficos resultados si es adecuadamente manejada (Ostrom 2005, pp. 651-664). Ostrom en esta argumentación resalta además algo evidente y ya comentado: el comportamiento de los funcionarios públicos $-\mathrm{y}$ de cualquier otro agente- depende también de su formación y de sus experiencias (North, 2005).

En este punto es importante señalar que las normas y rutinas resultado de la combinación entre inercias del pasado y las acciones colectivas y públicas pueden conducir a cometer errores, es decir a que se produzcan significativos desajustes entre las consecuencias de lo que se hace y las consecuencias deseadas (Thaler, 2016, pp. 425-490). Es decir, las normas y rutinas disponibles en un momento dado no tienen que ser necesariamente las más adecuadas para conducir los comportamientos hacia los objetivos implícitos en los valores de una sociedad y en los proyectos de sus ciudadanos y organizaciones. Hay pues un amplio campo abierto al asesoramiento de investigadores externos y, en este contexto, la economía del comportamiento, enfrentada a la selección de propuestas impulsoras del desarrollo económico mediante experimentos aleatorios, nos muestra una línea de investigación muy complementaria con las propuestas de Ostrom al desconfiar de las soluciones genéricas y sugerir reformas contrastadas empíricamente en los ámbitos que van a ser aplicadas (Karlan y Appel, 2011, pp. 15-32). ${ }^{42}$

Recapitulando, Olson nos da una imagen de la sociedad en la que los particulares tienen incentivos y capacidades para la producción de bienes privados, pero graves incapacidades individual y colectivamente para producir bienes públicos en cantidades y composición adecuadas. Es decir, no serían capaces de construir por sí mismos las condiciones que hagan viable la cooperación continuada y eficaz entre ellos. Sería el Estado con su capacidad coactiva quien construiría la sociedad. Sin embargo, Hayek, North y Ostrom nos muestran la capacidad autónoma de la sociedad de generar y hacer cumplir las normas y valores que ordenan la convivencia. Hayek además, con su concepto de orden espontáneo, resalta la capacidad autónoma de los agentes económicos de aprovechar la información y los recursos dispersos. Ostrom, al destacar la viabilidad y potencialidad de las acciones colectivas, nos muestra la amplia capacidad de los grupos sociales de ir dando solución a múltiples dilemas sociales. En consecuencia, resulta conveniente repensar el papel del Estado en la sociedad desde la perspectiva de que otros realizan tareas que se venían presuponiendo tan solo, o casi exclusivamente, propias del sector público (Ostrom, 2010). En cualquier caso, cualquiera de estos agentes, ya sean individuales, colectivos o públicos, pueden ser inductores tanto de efectos externos positivos como negativos. El asunto es identificar las circunstancias que condicionan la dirección de la interacción entre ellos. ${ }^{43}$ Además, como señala Thaler (2016), aun en las circunstancias aparentemente más favorables, no tienen por qué seleccionarse las normas y las rutinas más adecuadas para el logro de los objetivos deseados, la investigación empírica para testar normas alternativas podrá ocupar por tanto un lugar relevante en la orientación de las decisiones individuales, colectivas o públicas.

\footnotetext{
${ }^{42}$ El análisis de la gestión de los microcréditos (Karlan y Appel, 2011, pp. 111-140) resulta especialmente interesante al combinar la perspectiva de los prestamistas, de los prestatarios y sus repercusiones para el desarrollo económico. La relación entre los préstamos colectivos y las acciones colectivas entre los prestatarios resulta especialmente interesante en el contexto de la relación de la economía del comportamiento con las propuestas de Ostrom.

${ }^{43}$ En trabajos anteriores he intentado una síntesis de los requisitos para que una sociedad crezca equilibradamente (Gallego, 2007, pp. 150-166 y 2013, pp. 2-5).
} 
Pero a su vez hemos visto que una cosa es el papel que se considera teóricamente oportuno para el Estado y otro el papel que efectivamente desempeña y, este último es resultado en buena medida de las características de la sociedad en la que esa organización ejerce su soberanía. Pero tampoco debemos perder de vista que esa influencia de la sociedad sobre el Estado está filtrada por las características del sistema político y por la de los grupos concretos que en cada momento ejercen más influencia sobre su gran diversidad de ámbitos de actuación. Tampoco se debe prescindir de la imagen del Estado como una organización con su propia inercia, que no necesariamente tiene que ser la adecuada para la prosperidad general.

El cruce entre este conjunto de condicionantes de la acción pública se realiza mediante conflictos y negociaciones y en algunos casos mediante enfrentamientos abiertos. Pero el conflicto no está solo ni principalmente ligado al control de la acción pública, sino que también está presente en las relaciones entre agentes propia del orden espontáneo, así como en el despliegue de acciones colectivas con objetivos encontrados o entre los agentes que organizan cada una de ellas. Pero en estos conflictos pueden descubrirse también un campo para el consenso que nos debe pasar desapercibido (Polanyi, 1957).

\section{Conclusiones}

Con la excepción de la escuela austriaca, hay un amplio consenso sobre la relación entre la dotación de bienes públicos y preservación de los comunes y la viabilidad y grado de eficacia del funcionamiento de cualquier sistema económico. Cualquier sociedad para funcionar correctamente necesita proveerse de bienes públicos y preservar los bienes comunes. Una concepción más amplia de lo que son bienes públicos y comunes, y una mayor preocupación por la producción y preservación de unos y otros, permitirán crecer de modo más equilibrado y más seguro tanto desde la perspectiva social como ambiental. Es decir, la amplia preocupación por los bienes públicos y comunes permitirá crecer preservando la confianza, difundiendo el cocimiento, las experiencias y la salud entre los miembros de la sociedad, frenando la discriminación por cualquier razón de entre las muchas posibles, potenciando consiguientemente las capacidades individuales y colectivas e induciendo a pautas de comportamiento respetuosas con el medio ambiente.

Pero ¿cuáles son los contextos que inducen a la inmensa mayoría de los agentes económicos a la preocupación por disponer de una amplia y diversificada dotación de bienes públicos y comunes?

La idea que transmiten, globalmente considerados, los principios de Ostrom (2005, pp. 593630) es que en un contexto donde domine la reciprocidad -y con ellas la confianza- y en el que las personas perciban de modo efectivo su capacidad de participar en el autogobierno colectivo -y de influir en las decisiones públicas- será el adecuado para que las acciones de los distintos agentes conduzcan paulatinamente al establecimiento de unos principios y normas convenientes para un desenvolvimiento económico social y ambientalmente equilibrado.

Pero claro, queda pendiente otra pregunta: ¿cómo se consigue ese contexto en el que los agentes sean recíprocos y se sientan coprotagonistas del sostenimiento y rediseño del sistema institucional en el que se desenvuelven?

Bhaduri (1998) sugiere que el carácter más o menos equilibrado de las soluciones que se vayan dando a los conflictos dependerá de las posibilidades de que las partes implicadas dispongan de alternativas a la relación que haya provocado el conflicto. Disponer de otras oportunidades permite no tener que conformarse con las propuestas de los más poderosos. Estos a su vez, conocedores de las alternativas de las que los otros disponen, tenderán a ser más considerados en sus propuestas.

A su vez, tanto Bhaduri como Sen (1995 y 1999) coinciden en que "nada es gratis". Que la reciprocidad y la consideración en los procesos de toma de decisiones hay que arrancarlas negociando de un modo u otro. Hay circunstancias que mejoran sensiblemente la capacidad de negociación de los más débiles, como la citada disponibilidad de alternativas. Pero también, como nos señala Sen con su concepto de agencia, los agentes que se enfrentan a cualquier proceso de negociación o a cualquier conflicto necesitan también capacidades propias, información y relaciones con otros. Las relaciones pueden ser claves en algunos momentos para encontrar respaldo, o canales para difundir la voz, o para ejercer la salida en busca de nuevas alternativas 
(Hirschman 1970, 1984, 1991 y 1993). También serán necesarias para desarrollar acciones colectivas que permitan gestionar más eficazmente los conflictos o incluso organizar alternativas. Las relaciones a su vez tienden a ser más abundantes y variadas en sociedades donde hay más posibilidades de creación de vínculos débiles entre personas, empresas o investigadores (Putnam, 2002). La propia gestión colectiva de los conflictos frente a otros grupos puede crear a su vez las condiciones para descubrir nuevos espacios para el entendimiento tanto entre las partes como en el interior de cada uno de los grupos enfrentados (Polanyi, 1957). Las sociedades más habituadas a consensuar unos con otros tendrán unas inercias que facilitará el acordar normas equilibradas con los intereses de los distintos grupos en conflicto, y ello tanto el ámbito particular como en colectivo o en el público. ${ }^{44}$

\section{Bibliografía}

Acemoglu, Daron y Robinson, James A. 2006. Economic Origins of Dictatorship and Democracy. Cambridge, Cambridge University Press.

- 2012. Los orígenes del poder, la prosperidad y la pobreza ¿Por qué fracasan los países? Barcelona, Deusto.

Alonso, José Antonio y Garcimartín, Carlos. 2008. Acción colectiva y desarrollo. El papel de las instituciones. Madrid, Editorial Complutense.

Aumann, Robert. 2012. La teoría de los juegos. Conversaciones con Sergiu Hart. Salamanca, Ediciones Sígueme.

Becker, Gary S. 2001[1968]. Crimen y castigo: un enfoque económico. En Febrero, Ramón y Schwartz, Pedro (eds.), La esencia de Becker. Barcelona. Ariel, 455-502.

- [1976] 2001. El enfoque económico del comportamiento humano. En Febrero, Ramón y Schwartz, Pedro (eds.), La esencia de Becker. Barcelona. Ariel, 47-58.

Beltrán, Francisco. 2013. Enclosing literacy? Common lands and human capital in Spain, 18601930, Journal of Institutional Economics, 9 (4) , 491-515.

- 2015. Commons and the standard of living debate in Spain, 1860-1930, Cliometrica, 9 (1), 27-48.

-2016. Common Lands and Economic Development in Spain, Revista de Histioria Económica, Journal of Iberian and Latin American Economic History, 34 (1), 111-133.

Binmore, Ken. 2009. La teoría de los juegos. Una breve introducción. Madrid, Alianza.

Bhaduri, Amit. 1998. Eficiencia económica e instituciones agrarias, Historia Agraria, 15, 15 25.

Bobbio, Norberto. 1992 [1976]. La teoría de las formas de gobierno en la historia del pensamiento político. México, Fondo de Cultura Económica.

Buchanan, James M. y Tullock, Gordon. 2014 [1962]. El cálculo del consenso. Fundamentos lógicos de la democracia constitucional. Pamplona, Aranzadi.

Burke, Edmund. 2016 [1790]. Reflexiones sobre la Revolución Francesa. Madrid, Alianza.

Coase, Ronald H. 1994 [1937]. La naturaleza de la empresa. En Coase Ronald H., La empresa el mercado la ley. Madrid, Alianza, pp. 33-49.

- 1994 [1960]. El problema del coste social. En Coase, Ronald H., La empresa el mercado la ley. Madrid, Alianza, pp.121-164.

Delgado, Alva. 2015. La conciencia de lo común frente a la dicotomía Estado-Mercado. Análisis de la perspectiva de Elinor Ostrom (1933-2012). Tesis doctoral inédita presentada en la Facultad de Ciencias Económicas y Empresariales de la Universidad Complutense de Madrid.

De Vries, Jan. 2014. The Netherlands and the Polder Model: Questioning the Polder Model Concept, Low Countries Historical Review, 129 (1), 99-111.

Douglas, Mary 1996 [1986]. Cómo piensan las instituciones. Madrid, Alianza.

\footnotetext{
${ }^{44}$ El "polder model" referido a Holanda es un buen ejemplo de una sociedad trabada de instituciones que facilitan los acuerdos y que estos no sean muy desequilibrados (para un análisis crítico del concepto véase De Vries 2014).
} 
Gallego, Domingo. 2007. Más allá de la economía de mercado. Los condicionantes históricos del desarrollo económico. Madrid, Marcial Pons y Prensas Universitarias de Zaragoza.

- 2013. Respeto y prosperidad. Documento de trabajo $n^{\circ} 721$ de la Fundación de las Cajas de Ahorro (FUNCAS): http://www.funcas.es/publicaciones/Sumario.aspx?IdRef=7-05720

Garrido, Samuel. 2011. Las instituciones de riego en la España del este. Una reflexión a la luz de la obra de Elinor Ostrom, Historia Agraria, 53, 13-42.

Gauthier, David, 1998 [1997]. Contractualismo político. En Gauthier, David, Egoísmo, moralidad y sociedad liberal. Buenos Aires, Paidós, 161-185.

Granovette, Mark S. 2000 [1973]. La fuerza de los vínculos débiles, Política y Sociedad, 33, 4153.

Hardin, Garrett, 1968. The Tragedy of Commons, Science, 162, 1243-1248.

Hayek, Friedrich A. 1978 [1944]. Camino de servidumbre. Madrid, Alianza.

—1985, 1988, 1982 [1973, 1976 y 1979]. Derecho, legislación y libertad. Una nueva formulación de los principios liberales de la justicia y de la economía política. Madrid, Unión Editorial (3 vols.).

Henrich, Joseph; Boyd, Robert; Bowles, Samuel; Camerer, Colin; Fehr, Ernst; Gintis, Herbert y McElreath, Richard. 2001. In Search of Homo Economicus: Behavioral Experiments in 15 Small-Scale Societies. The American Economic Review, 91 (2), 73-78.

Hirschman, Albert O. 1977 [1970]. Salida, voz y lealtad. México, Fondo de Cultura Económica.

-1986 [1984]. El avance en colectividad. Experimentos populares en la América Latina. México, Fondo de Cultura Económica.

- 1994 [1991]. Retóricas de la intransigencia. México, Fondo de Cultura Económica.

-1996 [1993]. Salida, voz y el destino de la RDA. Un ensayo de historia conceptual. En Hirschman, Albert O., Tendencias autosubersivas. Ensayos. México, Fondo de Cultura Económica, 15-55.

Hodgson, Geoffrey M. 1995 [1993]. Economía y evolución. Revitalización de la Economía. Madrid, Colegio de Economistas de Madrid-Celeste Ediciones.

Hume, David. 1988 [1739-1740]. Tratado sobre la naturaleza humana. Madrid, Tecnos.

Jasay, Anthony.1985. El Estado. La lógica del poder político. Madrid, Alianza.

Karlan, Dean y Appel, Jacob. 2011. ¡No basta con buenas intenciones! Cómo la nueva economía del comportamiento ayuda a vencer la pobreza en el mundo. Barcelona, Bosch.

Lana, José Miguel y Laborda, Miguel. 2013. El anidamiento institucional y su dinámica histórica en comunidades rurales complejas. Dos estudios de caso (Navarra, siglos XIV-XX), Documentos de trabajo de la Sociedad Española de Historia Agraria DT-SEHA, 13-07: http://ideas.repec.org/p/seh/wpaper/1307.html

Laval, Christian y Dardot, Pierre. 2015. Común. Ensayo sobre la revolución en el siglo XXI. Barcelona, Gedisa.

Mises, Ludwig. 1947. Epílogo. En Ludwig Mises, Socialismo. Análisis económico y sociológico. Buenos Aires, Western Books Foundation, 537-608.

Morris, Ian. 2016. Cazadores, campesinos y carbón. Una historia de los valores de las sociedades humanas. Barcelona, Ático de los Libros.

Mokyr, Joel. 2008 [2002]. Los dones de Atenea. Los orígenes históricos de la economía del conocimiento. Madrid, Marcial Pons.

Mueller, Dennis C. 2003. Public choice III. Cambridge (UK), Cambridge University Press.

Nell, Edward J. 1999. El crecimiento transformativo. En Brical, Josep M. y de Juan, Óscar (eds.), Economía política del crecimiento, fluctuaciones y crisis. Barcelona, Ariel, 15-43.

Nelson, Richard R. 2008. What enables rapid economic progress: What are the needed institutions? Research Policy, 37, 1-11.

North, Douglass C. 1984 [1981]. Estructura y cambio en la historia económica. Madrid, Alianza Editorial.

— 1993 [1990]. Instituciones, cambio institucional y desempeño económico. México, Fondo de Cultura Económica.

- 2005. Understanding the process of economic change. Princeton (N.J.), Princeton University Press. 
Olson, Mancur. 1992 [1971]. La lógica de la acción colectiva. Bienes públicos y teoría de grupos. México, Noriega Editores.

- 1982. Auge y decadencia de las naciones. Barcelona, Ariel.

— 2001 [2000]. Poder y prosperidad. Madrid, Siglo XXI.

- 2008 [1990]. Governing the commons. The evolution of institutions for collective action. Cambridge, Cambridge University Press.

Ostrom, Elinor. 2013 [2005]. Comprender la diversidad institucional. Oviedo, KRK Ediciones.

- 2010. Beyond Markets and States: Polycentric Governance of Complex Economic Systems. American Economic Review, 100, 641-672.

Ostrom, Elinor y Ahn, Toh-Kyeong. 2003. Una perspectiva del capital social desde las ciencias sociales: capital social y acción colectiva, Revista Mexicana de Sociología, 65 (1), 155-233.

Planas, Jordi y Valls-Junyent, Francesc. 2011. ¿Por qué fracasaron las cooperativas agrícolas? Una respuesta a partir del análisis de la Cataluña rabasaire, Investigaciones de Historia Económica, 7 (2), 310-321.

Polanyi, Karl. 1992 [1957]. La gran transformación. Los orígenes políticos y económicos de nuestro tiempo. México, Fondo de Cultura Económica.

Putnam, Robert D. 2002. Solo en la bolera. Colapso y resurgimiento de la comunidad norteamericana. Barcelona, Galaxia Gütenberg/Círculo de Lectores.

Salas, Vicente. 2007. El siglo de la Empresa. Bilbao, Fundación BBVA.

Sen, Amartya. 2001 [1995]. Las teorías del desarrollo en el siglo XXI, Leviatán, 84, 65-84.

- 2000 [1999]. Desarrollo y libertad. Barcelona, Planeta.

Thaler, Richard H. 2016. Todo lo que he aprendido con la psicología económica. Barcelona, Deusto.

Tomasello, Michael. 2010. ¿Por qué cooperamos? Madrid, Katz.

Tullock, Gordon. 2006 [1976]. The Vote Motive. London, The Institute of Economic Affaires.

Williamson, Oliver E. y Winter, Sindney G. 1996. La naturaleza de la empresa. Orígenes, evolución y desarrollo. México, Fondo de Cultura Económica.

- 2009 [1985]. Las instituciones económicas del capitalismo. México, Fondo de Cultura Económica. 